\title{
Magnetic Resonance Imaging of Hard Tissues and Hard Tissue Engineered Bio-substitutes
}

\author{
Simone Mastrogiacomo $\odot,{ }^{1,2}$ Weiqiang Dou, ${ }^{3,4}$ John A. Jansen, ${ }^{1}$ X. Frank Walboomers ${ }^{1}$ \\ ${ }^{1}$ Department of Biomaterials, Radboud University Medical Center, Philips van Leijdenlaan 25, 6525 EX, Nijmegen, The Netherlands \\ ${ }^{2}$ Laboratory of Functional and Molecular Imaging, NINDS, National Institutes of Health, Building 10, 5S261, Bethesda, MD, 20892, USA \\ ${ }^{3}$ Department of Radiology and Nuclear Medicine, Radboud University Medical Center, Geert Grooteplein Zuid 10, 6525 GA, Nijmegen, \\ The Netherlands \\ ${ }^{4}$ GE Healthcare, MR Research, Beijing, People's Republic of China
}

\begin{abstract}
Magnetic resonance imaging (MRI) is a non-invasive diagnostic imaging tool based on the detection of protons into the tissues. This imaging technique is remarkable because of high spatial resolution, strong soft tissue contrast and specificity, and good depth penetration. However, MR imaging of hard tissues, such as bone and teeth, remains challenging due to low proton content in such tissues as well as to very short transverse relaxation times $\left(\mathrm{T}_{2}\right)$. To overcome these issues, new MRI techniques, such as sweep imaging with Fourier transformation (SWIFT), ultrashort echo time (UTE) imaging, and zero echo time (ZTE) imaging, have been developed for hard tissues imaging with promising results reported. Within this article, MRI techniques developed for the detection of hard tissues, such as bone and dental tissues, have been reviewed. The main goal was thus to give a comprehensive overview on the corresponding (pre-) clinical applications and on the potential future directions with such techniques applied. In addition, a section dedicated to MR imaging of novel biomaterials developed for hard tissue applications was given as well.
\end{abstract}

Key words: Ultrashort Echo Time MRI, Bone, Teeth, Biomaterials

\section{Introduction}

Magnetic resonance imaging (MRI) is a non-invasive imaging technology that performs three-dimensional (3D) imaging for body organs with high spatial resolution $(<1 \mathrm{~mm})$. The primary advantage of MRI is to allow for obtaining crosssectional anatomical information of the organs due to an excellent soft tissue contrast and excellent depth penetration. Furthermore, MRI offers functional information based on various tissue properties, such as proton density, temperature, biochemical content, oxygen level, and $\mathrm{pH}[1,2]$.

Correspondence to: Simone Mastrogiacomo; e-mail: simone.mastrogiacomo@nih.gov
Since MRI has been applied in the clinic in early 1980s, the number of MR examinations has tremendously increased especially for pathologies related to brain, spine, abdomen, cardiovascular, and muscular systems [3,4]. To date, the state-of-art MRI techniques include 1) MR spectroscopy (MRS) and chemical shift imaging (CSI), which permit the identification and classification of tumors through the assessment of the chemical metabolism in a specific area of the body; 2) functional MRI (fMRI), which is able to image the neuronal activity through the detection of the blood oxygenation level-dependent (BOLD) changes occurring in the brain; and 3) MR elastography (MRE), which can be used for the characterization of the biomechanical properties of soft tissues by the visualization of propagating shear waves [5-7]. 
Despite the wide use of MRI as a diagnostic tool for soft tissues, its application for hard tissues (i.e., bone and teeth) remains challenging. The water content in such tissues is usually very low $(<20 \% v / v)$ and mainly trapped in a solid phase leading to a very short relaxation profile. Therefore, the signal decays significantly before the detection by conventional MRI techniques, which results in a dark and undefined image [8]. Over the last decade, newly developed MRI techniques that are able to image tissues with very low water content and ultrashort $\mathrm{T} 2$ relaxation times have been reported. The most promising techniques include ultrashort echo time (UTE) imaging, zero echo time (ZTE) imaging, and sweep imaging with Fourier transformation (SWIFT).

Thus, after a general introduction about basic principles of MRI, bone-specific MRI sequences, and anatomical and chemical compositions of hard tissues, this review mainly emphasizes all the progresses that have been made on ultrashort MRI acquisitions of such tissues in terms of sequence development, possible clinical translations, and related strengths and weaknesses. Finally, this review focused also on a fast-growing application of such MRI sequences, i.e., acquisition and in vivo monitoring of biomaterials intended to bone and dental restoration.

\section{Basic Principles of MRI}

MR imaging was evolved from the basic physical principles of nuclear magnetic resonance (NMR). Typically, MRI is used to detect the nucleus of hydrogen $\left(\mathrm{H}^{+}\right)$in the water molecules as present in the body. Protons are positively charged subatomic particles that are constantly rotating along their axis. The rotational movement of protons in an atom gives rise to a quantum-mechanic atomic property that is called spin. Only unpaired protons exhibit spin, which is the case of atoms with an odd number of protons and neutrons, whereas atoms with an equal number of protons and neutrons exhibit a null overall spin. The spinning motion of an electric charge generates a magnetic field, hence each proton can be considered as a small bar magnet and described as a vectoral force, named magnetic moment, with a random orientation (Fig. 1a). When an external magnetic field $\left(\mathrm{B}_{0}\right)$ is applied to a proton, its magnetic moment will align to the direction of $\mathrm{B}_{0}$ and have only two possible orientations, i.e., parallel to $\mathrm{B}_{0}(\operatorname{spin}=1 / 2)$, and antiparallel to $\mathrm{B}_{0}$ (i.e., $\mathrm{spin}=-1 / 2$ ). The speed of the precession movement of the proton is described by the Larmor frequency $(\omega)$ with unit of $\mathrm{rad} / \mathrm{s}$, and depends on the strength of the applied $\mathrm{B}_{0}$ with unit of Tesla (T), and on gyromagnetic ratio $(\gamma)$ according to the following formula $\omega=\gamma \mathrm{B}_{0}$, where $\gamma$ is a constant describing the gyromagnetic ratio of a particular nuclear species (i.e., for proton $\gamma=$ $\left.267.56 \times 10^{6} \mathrm{rad} / \mathrm{s} / \mathrm{T}\right)$. If to the static $\mathrm{B}_{0}$ a second alternating magnetic field $\left(\mathrm{B}_{1}\right)$ is applied in the orthogonal direction, it is possible to disturb the magnetic moment of the proton from the $\mathrm{B}_{0}$ direction. The alternating magnetic field $\mathrm{B}_{1}$ is usually referred as radio frequency (RF) and must have the same Larmor frequency as the investigated nucleus. In this way, the applied RF is able to induce a transfer of energy to the protons with a rotation angle determined by the amplitude and duration of B1 (Fig. 1a). When the RF is switched off, the protons tend to return to their equilibrium status in a process known as relaxation.

During relaxation, protons lose energy according to two processes known as longitudinal relaxation $\left(\mathrm{T}_{1}\right)$ and transverse relaxation $\left(\mathrm{T}_{2}\right)$ (Fig. 1b, c). The longitudinal relaxation describes the process whereby the adsorbed energy is released to the surrounding nuclei, inducing an increase of vibration within the lattice that results in an increase of thermal energy. Hence, longitudinal relaxation is also named spin-lattice relaxation, while $\mathrm{T}_{1}$ relaxation refers to the time needed by the magnetization moment $\mathrm{M}_{\mathrm{z}}$ to reach $63 \%$ of the original position (i.e., $\mathrm{M}_{0}$, Fig. $1 \mathrm{~b}$, d). Transverse relaxation describes the process whereby the adsorbed energy is released by spins as a consequence of random mutual interference between each other, hence also known as spin-spin relaxation. $T_{2}$ relaxation refers to the time needed by the magnetization moment $\mathrm{M}_{\mathrm{xy}}$ to decay to a $37 \%$ of its initial value (Fig. 1c, e). Pure $\mathrm{T}_{2}$ decay is happening theoretically only with a completely homogeneous $\mathrm{B}_{0}$. However, this is never the case, as tissues with different susceptibility properties can affect the homogeneity of the magnetic field. These inhomogeneities are described by a $\mathrm{T}_{2}{ }^{*}$ constant (Fig. 1e). As tissues have different relaxation properties, an image can be generated based on the differences in $\mathrm{T}_{1}$ (i.e., $\mathrm{T}_{1}$-weighted image, Fig. 1d) and in $\mathrm{T}_{2}$ (i.e., $\mathrm{T}_{2}$-weighted image, Fig. 1e) relaxation properties $[1,9,10]$.

The position of the spins into the space is defined through three separate magnetic field gradients named slice-selection gradient, phase-encoding gradient $\left(\mathrm{G}_{\mathrm{P}}\right)$ and frequency encoding gradient $\left(\mathrm{G}_{\mathrm{F}}\right)$. Firstly, a slice into the object is selected through the slice-selection gradient that generates a gradient field along the chosen axis, thus altering $\mathrm{B}_{0}$ in the chosen direction. Usually, a RF is applied to excite a slice with a defined thickness which makes the protons precess in phase. Afterwards, the $G_{P}$ is applied, which induce the protons to precess at different speeds according to their positions. When $G_{P}$ is turned off, the protons have the same precession frequency, but they will be no longer in phase. Finally, $G_{F}$ is applied perpendicularly along $G_{P}$ direction inducing the protons to rotate at different frequencies according to their relative positions. A mathematical algorithm known as Fourier transform (FT) is used to define the position of the protons based on the frequency analysis of the measured MRI signal [9]. Specifically, FT is able to convert the frequency data (in $\mathrm{Hz}$ ) in spatial information (in $\mathrm{mm}$ ) that are collected in the so-called k-space. In a 2D acquisition, the k-space consists of a two-dimensional matrix with $\mathrm{Kx}$ and $\mathrm{Ky}$ coordinates corresponding to the $\mathrm{x}-$ and $\mathrm{y}-$ axis, respectively. Therefore, the location of the spins can be defined based on their spatial frequency in the $\mathrm{Kx}$ and $\mathrm{Ky}$ directions of the k-space $[11,12]$. 
a

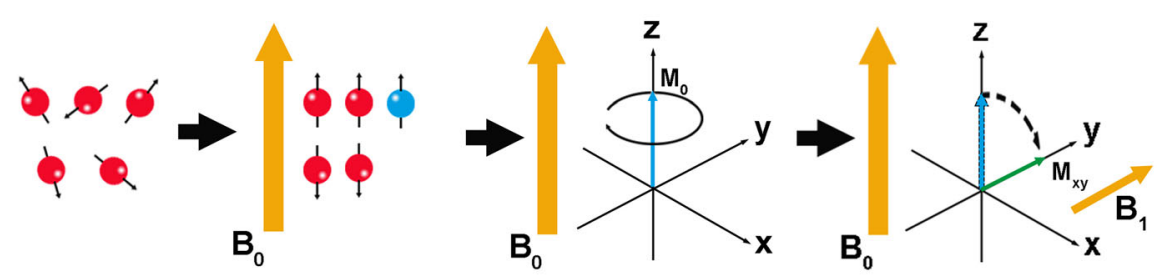

b

\section{$T_{1}$ relaxation}

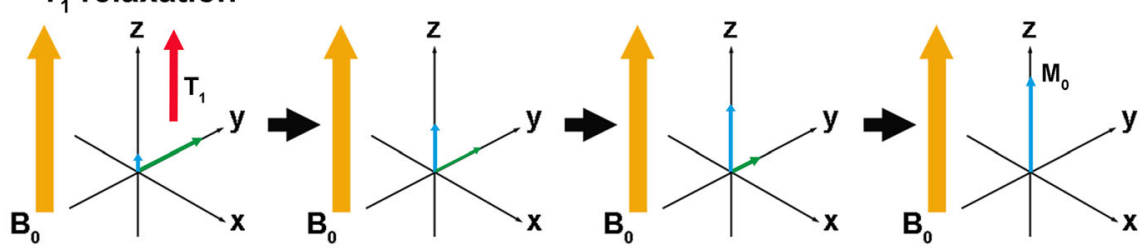

\section{C}

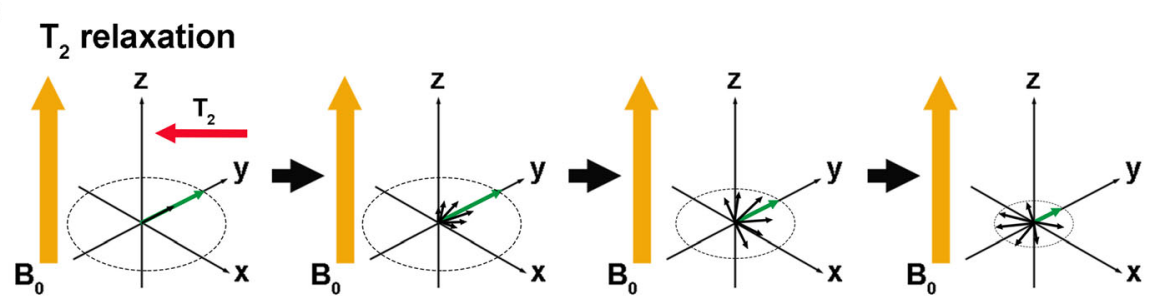

d

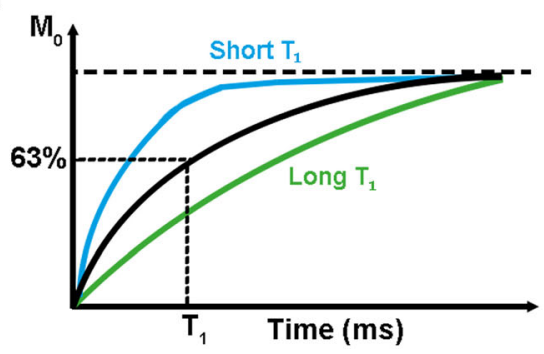

e

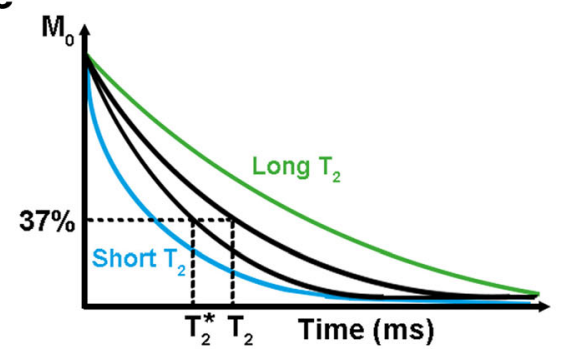

Fig. 1. Schematic representation of the basic principles of MRI. a Protons are represented as red balls spinning around their own axis. When an external magnetic field $\mathrm{B}_{0}$ (orange arrow) is applied, protons tend to align with the direction of $\mathrm{B}_{0}$ and have only two possible orientation, spin-up, and spin-down. The difference between the protons aligned parallel and antiparallel to $\mathrm{B}_{0}$ (blue ball) represents the protons that are responsible for the MRI signal. The sum of these protons can be described by a magnetization vector $\left(M_{0}\right.$, blue arrow). If a second magnetic field $\left(B_{1}\right)$ orthogonal to $B_{0}$ is applied, it is possible to tilt $M_{0}$ of $90^{\circ}$ along the $x-y$ direction $\left(M_{x y}\right.$, green arrow). When $B_{1}$ is switched off, $M_{x y}$ returns to the equilibrium through two processes: $T_{1}$ and $T_{2}$ relaxation. The schematic representation of $\mathbf{b} T_{1}$ and $\mathbf{c} T_{2}$ relaxation are shown respectively. $\mathbf{d} T_{1}$ relaxation is defined as the time needed to achieve the $63 \%$ of the original longitudinal magnetization. Blue curve and the green curve represent tissues with short and long $T_{1}$ values, respectively. $\mathbf{e} T_{2}$ relaxation is defined as the time to dephase up to $37 \%$ of the original value. Blue curve and the green curve represent tissues with short and long $T_{2}$ values, respectively. Adapted from [1, 9].

Tissues with a high free water content, such as blood, brain, skeletal muscle, and spinal cord, show long $T_{2}$ and $\mathrm{T}_{1}$ relaxation times, which can generate a relatively strong signal in MRI [13]. By contrast, in tissues with low water content where the protons are trapped in a rigid crystal phase, such as bone and teeth, the signal decays quickly, resulting to a dark image with no discernible structured contrast (Table 1) [8, 14]. This review focused on the tissues with short $\mathrm{T}_{2}$ relaxation time that are commonly classified as tissue with short (i.e., $\mathrm{T}_{2}=1-10 \mathrm{~ms}$ ), ultrashort (i.e., $\mathrm{T}_{2}=0.1-1 \mathrm{~ms}$ ), and supershort relaxation (i.e., $\left.\mathrm{T}_{2}<0.1 \mathrm{~ms}\right)$ [15].

\section{Basic Principle of Ultrashort Echo Time Imaging}

UTE imaging refers to MRI sequences that can be used to image tissues with a $T_{2}$ shorter than $10 \mathrm{~ms}$. The basic $2 \mathrm{D}$ UTE sequence uses two short half RF pulses: the first pulse uses a negative gradient and the second pulse uses a positive gradient, which together result in the same scenario as a single complete excitation pulse. Data acquisition starts as long as the readout gradient is being activated (Fig. 2a) [8, 14-16]. The detected data are added together to provide one line into the k-space that starts from the center of the k-space and proceeds radially. This process, known as radial 
Table 1. $\mathrm{T}_{1}$ and $\mathrm{T}_{2}$ of tissues and tissue components measured at $1.5 \mathrm{~T}$. Adapted from $[13,14]$

\begin{tabular}{lll}
\hline Tissue & $\mathrm{T}_{1}$ & $\mathrm{~T}_{2}$ \\
\hline Blood & $1441 \mathrm{~ms}$ & $290 \mathrm{~ms}$ \\
Gray matter & $1124 \mathrm{~ms}$ & $95 \mathrm{~ms}$ \\
Skeletal muscle & $1008 \mathrm{~ms}$ & $44 \mathrm{~ms}$ \\
Heart & $1030 \mathrm{~ms}$ & $40 \mathrm{~ms}$ \\
White matter & $884 \mathrm{~ms}$ & $72 \mathrm{~ms}$ \\
Spinal cord & $745 \mathrm{~ms}$ & $74 \mathrm{~ms}$ \\
Kidney & $690 \mathrm{~ms}$ & $55 \mathrm{~ms}$ \\
Ligaments & - & $4-10 \mathrm{~ms}$ \\
Knee menisci & - & $5-8 \mathrm{~ms}$ \\
Periosteum & - & $5-11 \mathrm{~ms}$ \\
Cortical bone & $398 \mathrm{~ms}$ & $0.4-0.5 \mathrm{~ms}$ \\
Dentin & - & $0.15 \mathrm{~ms}$ \\
Dental enamel & - & $70 \mu \mathrm{s}$ \\
Protons in proteins & - & $10 \mu \mathrm{s}$ \\
\hline
\end{tabular}

mapping of the $\mathrm{k}$-space, is repeated through all $360^{\circ}$, typically in 128-512 steps (Fig. 2b). The data are then gridded into a rectangular matrix, e.g., $512 \times 512$, and transformed into an image through a two-dimensional FT $[17,18]$.

As for the imaging of ultrashort $\mathrm{T}_{2}$ components, the signal need to be acquired as soon as the signal excitation ends, fast transmit/receiving switching coils, and dedicated hardware are demanded to minimize the signal decay. An optimal UTE acquisition does not necessarily imply to use a strong $\mathrm{B}_{0}$. Still, strong field strength for high signal-to-noise (SNR) is necessary to detect X-nuclei with lower signal sensitivity than ${ }^{1} \mathrm{H}$, such as phosphorous and sodium. Surely, the performance of the gradient, in terms of slew rate and amplitude, needs to be as high as possible, as it is necessary to ramp up the gradient really quickly after the RF pulse. Also, a high-performance RF receiver system is demanded to quickly receive the signal without losing any data [18]. Nevertheless, short receiver sampling period and high-demanding gradients required by UTE sequences induce eddy currents into the conducting structures of the scanner (e.g., gradient coils, shim coil, and other parts of the cryostat), which lead to imaging artifacts, localization errors, and signal distortions $[19,20]$. Imaging imperfections due to eddy currents are common also for MRI sequences based on non-Cartesian sampling acquisitions (e.g., radial and spatial imaging), and have been attenuated by using many strategies, such as pre-emphasis corrections, imaging-based gradient measurements (IGM), and gradient impulse response function (GIRF) [21, 22]. Jang $\mathrm{H}$ et al. [23] developed a measurement technique that allowed to overcome eddy current effects during UTE acquisitions. Such method is based on a ramped hybrid encoding (RHE) scheme that consists of an initial small gradient (e.g., below $7 \mathrm{mT} / \mathrm{m}$ ) during the RF excitation, which is used to minimize the slice selectivity, and a subsequent gradient ramping up to the maximum encoding amplitude, which is used to minimize the overall sampling duration. RHE-UTE showed improved spatial resolution for short $T_{2}$ species and reduced chemical shift artifacts when compared to standard 3D-UTE acquisitions. Furthermore, RHE-UTE can be further implemented by using a 1D dynamic single-point imaging (SPI) method, which allows high-resolution sampling of the k-space [24].

\section{Basic Principle of Zero Echo Time Imaging}

With the ZTE imaging techniques, the encoding gradient is switched on before the RF pulse excitation, hence resulting in a TE theoretically equal to zero. ZTE acquisition method uses a short hard-pulse excitation and small flip angle, while a

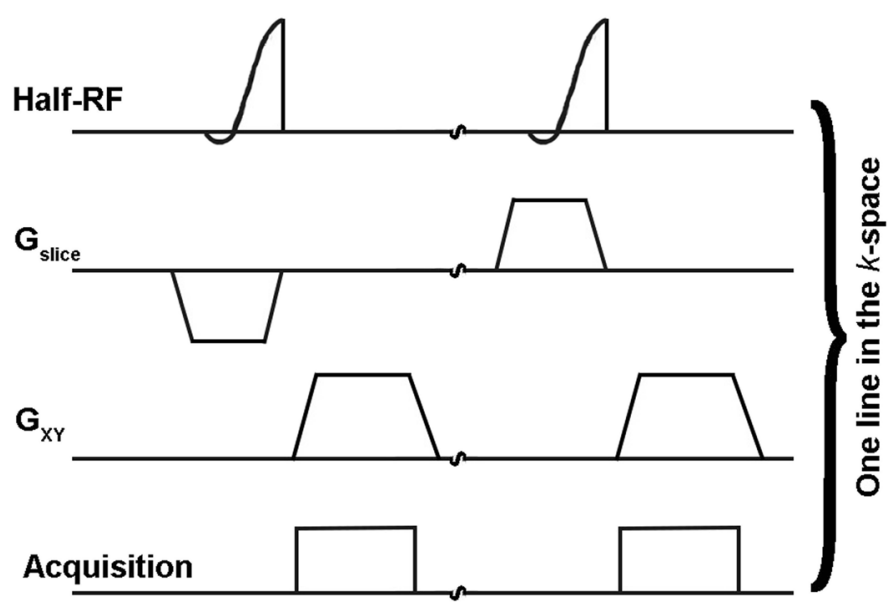

b

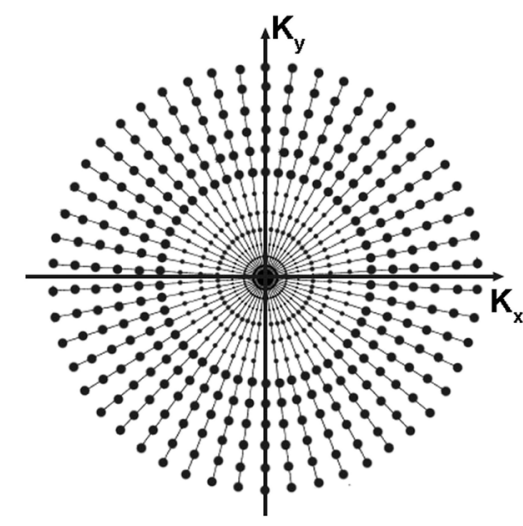

Fig. 2. Schematic representation of a basic $2 D$ UTE sequence. a The pulse diagram is reported: Note that two short half RF pulses are applied with the slice-selection gradient negative in the first half and with a slice-selection gradient positive in the second half $\left(G_{\text {slice }}\right)$. When the $R F$ is switched off, the radial gradients $G_{x y}$ are applied and the acquisition starts. b The acquired data give a line in the k-space. Each spoke represents the k-space trajectories due to the readout gradients. The small dots in the center are sampled during the gradient ramp; the big dots are sampled while the gradient reaches the plateau. For a typical acquisition 128-512 spokes and 256-512 point each spoke are used. Adapted from [8]. 
a

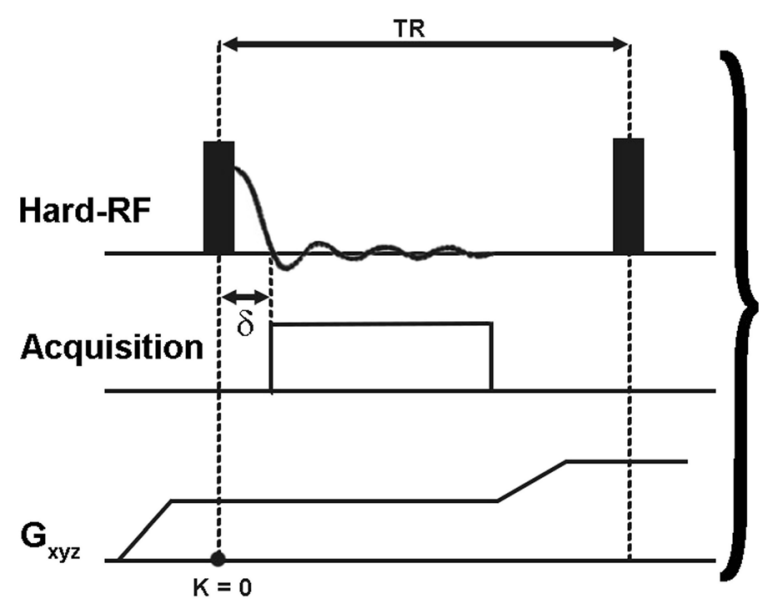

b

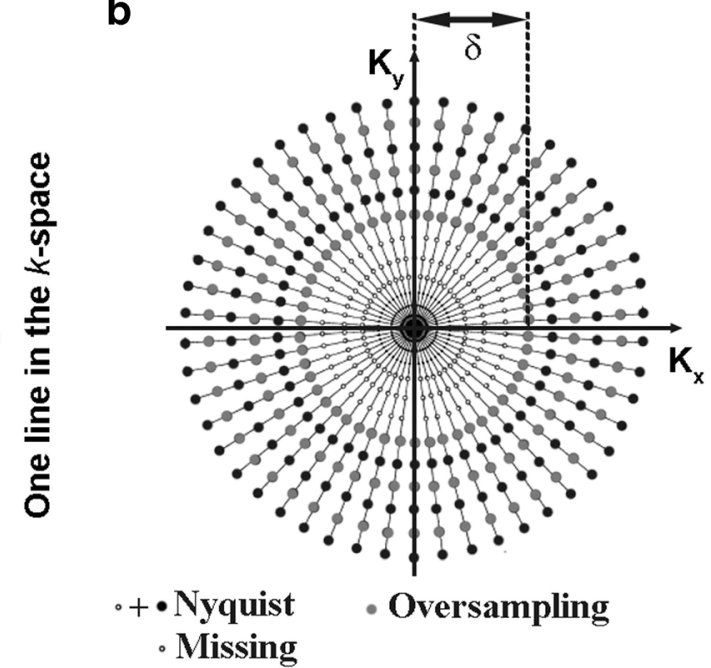

Fig. 3. Schematic representation of a basic ZTE sequence. a The pulse diagram is reported: Note that the gradient in a given direction is ramped up and followed by a hard RF pulse. Signal acquisition starts immediately resulting in a TE = zero. In the reality, the acquisition starts after a delay (ठ). $\mathbf{b}$ The acquired data give a line in the k-space shown. Big black dots and small empty dots represent the data points required for a complete projection. The small empty dots represent the points that are missed because of delay $(\delta)$. Gray dots indicate the additional point achieved through oversampling. Adapted from [25].

the gradients in the three directions are gradually reoriented (Fig. 3a). Therefore, ZTE sequences have more restrictions in flip angles and readout bandwidths compared to the UTE. However, a small step of changing gradients in three directions allows an acquisition with very low acoustic noise and reduces eddy current problems, making ZTE imaging highly robust. The k-space is filled through a 3D radial center-out method and then transformed by gridding and FT, as also is done for the UTE acquisitions. In the reality, after the RF excitation, the acquisition starts with a delay $(\delta)$ that is determined by the time needed for the transmit/receive switching. This gap of information can be filled by acquisition oversampling, which is performed through a linear algebra-based imaging reconstruction scheme (Fig. 3b). However, large oversampling increases the amount of data that requires a large memory in the computer for data processing $[25,26]$. Recently, Grodzki et al. [27] proposed a new method of filling the k-space based on a combination of radial mapping and Cartesian single point acquisition, also known as pointwise encoding time reduction with a radial acquisition (PETRA, Table 2). In this way, the gap in the middle of the k-space is filled with the exact value obtained from the single point acquisition. Therefore, every point in the k-space can be measured with the smallest encoding time. PETRA approach allows imaging with higher SNR, as more readout points with signal from tissue with short $T_{2}$ can be acquired before the signal decay. However, the PETRA method requires that the object to be imaged fits into the main lobe of the sincshaped excitation profile of the rectangular pulse. A suitable solution to this problem was proposed by Li et al. [37] who developed an algorithm for correcting artifacts based on a hard RF pulse modulated with a quadratic phase. This algorithm adapted to PETRA sequence showed the effectiveness to correct imaging artifacts caused by inhomogeneous excitation over the object, allowing to operate with longer RF pulse and lower peak power, hence suitable for clinical scanners. Therefore, PETRA-based MR imaging method has showed superiority in imaging performance when compared to the standard ZTE techniques and has been applied clinically on $1.5 \mathrm{~T}$ and $3 \mathrm{~T}$ MRI systems for the imaging of hard tissues [37, 39].

The development of speedy RF switching techniques and the demand for strong hardware that can handle the big amount of generated data stands as two technical challenges for the application of ZTE sequences in humans. Recently, Weiger et al. [35] implemented the ZTE method for human imaging by using a custom-made console, which includes a spectrometer and a pulse generator that allows a reduction of the excitation pulse to $3 \mu \mathrm{s}$ and the transmit/receive switching to $1 \mu \mathrm{s}$. The custom-built console was based on a packaged analog-to-digital converter (ADC) and a fieldprogrammable gate array (FPGA) combined with 1 terabyte (TB) redundant array of independent disks (RAID) for realtime data storage. However, a large excitation bandwidth with associated high specific absorption rate (SAR) and imaging artifacts were found to be the major concern [35].

Further ZTE imaging optimizations, which consisted of short amplitude- and frequency-modulated pulses for high bandwidth $\mathrm{RF}$ excitation, and long $\mathrm{T}_{2}$ suppression, led to a significant improvement of this technique for clinical use [40, 41].

\section{Basic Principle of Sweep Imaging with Fourier Transformation}

The SWIFT method, developed by Idiyatullin et al. [42, 43], can be considered as a combination of all three basic NMR 
Table 2. Ultrashort MRI sequences for bone

\begin{tabular}{ll}
\hline Name of the sequence & MRI settings
\end{tabular}

CUTE (conventional UTE)

FUTE (fat-suppressed UTE)

STUTE (short inversion time UTE)

MUTE (medium inversion time UTE)

UTE-OSC (off-resonance saturation contrast UTE)

IR-UTE (inversion recovery UTE)

UTE-PETRA (UTE-pointwise encoding time reduction with radial acquisition)

MT-UTE (magnetization transfer UTE)

UTE-FPE (fully phase-encoded)

3D IR-UTE-Cones

ZTE

ZTE-RUFIS (rotating ultrafast imaging sequence)
FOV $=26-38 \mathrm{~cm}$, section thickness $=4-8 \mathrm{~mm}$

$\mathrm{TR}=500 \mathrm{~ms}, \mathrm{TE}=80 \mu \mathrm{s}$

Second TE $=2.87,5.66,11.08,17.70 \mathrm{~ms}$

$\mathrm{RF}$ pulse $=0.4-0.6 \mathrm{~ms}, \mathrm{FA}=30^{\circ}-80^{\circ}$

$\mathrm{TA}=8.5-17 \mathrm{~min} .[28,29]$

FOV $=26-38 \mathrm{~cm}$, section thickness $=4-8 \mathrm{~mm}$

$\mathrm{TR}=500 \mathrm{~ms}, \mathrm{TE}=80 \mu \mathrm{s}$

Second $\mathrm{TE}=2.87,5.66,11.08,17.70 \mathrm{~ms}$

$\mathrm{RF}$ pulse $=10 \mathrm{~ms}, \mathrm{FA}=30^{\circ}-80^{\circ}$

$\mathrm{TA}=8.5-17 \mathrm{~min} .[28,29]$

FOV $=26-38 \mathrm{~cm}$, section thickness $=4-8 \mathrm{~mm}$

$\mathrm{TR}=2200 \mathrm{~ms}, \mathrm{TE}=80 \mu \mathrm{s}$

Second TE $=2.87,5.66,11.08,17.70 \mathrm{~ms}$

RF pulse $=0.4-0.6 \mathrm{~ms}, \mathrm{FA}=45^{\circ}$ or $80^{\circ}$

Inversion pulse $=4 \mathrm{~ms}, \mathrm{TI}=360$ or $380 \mathrm{~ms}$

$\mathrm{TA}=8.5-17 \mathrm{~min} .[28,29]$

FOV $=26-38 \mathrm{~cm}$, section thickness $=4-8 \mathrm{~mm}$,

$\mathrm{TR}=2500 \mathrm{~ms}, \mathrm{TE}=80 \mu \mathrm{s}$

Second $\mathrm{TE}=2.87,5.66,11.08,17.70 \mathrm{~ms}$

RF pulse $=0.4-0.6 \mathrm{~ms}, \mathrm{FA}=45^{\circ}$ or $80^{\circ}$

Inversion pulse $=4 \mathrm{~ms}, \mathrm{TI}=750 \mathrm{~ms}$

$\mathrm{TA}=8.5-17 \mathrm{~min} .[28,29]$

$\mathrm{FOV}=10 \mathrm{~cm}$, section thickness $=2-3 \mathrm{~mm}$

Gradient amplitude $=40 \mathrm{mT} / \mathrm{m}$

Slew rate $=150 \mathrm{mT} / \mathrm{m} / \mathrm{ms}$, Bandwidth $=62.5 \mathrm{kHz}$

$\mathrm{TR}=200-300 \mathrm{~ms}, \mathrm{TE}=8 \mu \mathrm{s}$

Fermi pulse $=16 \mathrm{~ms} /$ Hard pulse $=10 \mathrm{~ms}$

$\mathrm{TA}=4-10 \min [30]$

FOV $=10 \mathrm{~cm}$, section thickness $=6 \mathrm{~mm}$

Gradient amplitude $=40 \mathrm{mT} / \mathrm{m}$

Slew rate $=150 \mathrm{mT} / \mathrm{m} / \mathrm{ms}$, Bandwidth $=125 \mathrm{kHz}$

$\mathrm{TR}=300 \mathrm{~ms}, \mathrm{TE}=8 \mu \mathrm{s}$

Second TE $=4400 \mu \mathrm{s}, \mathrm{TI}=80,100,120,140,160 \mathrm{~ms}$

$\mathrm{FA}=60^{\circ}$, Spatial resolution $=0.2 \times 0.2 \times 6 \mathrm{~mm}^{3} \mathrm{TA}=9 \mathrm{~min}$. [31]

$\mathrm{FOV}=200 \mathrm{~mm}$, section thickness $=22 \mathrm{~mm}$

Gradient amplitude $=8-15 \mathrm{mT} / \mathrm{m}$

Slew rate $=100 \mathrm{mT} / \mathrm{m} / \mathrm{ms}$, Bandwidth $=86 \mathrm{kHz}$

$\mathrm{TR}=2-5 \mathrm{~ms}, \mathrm{TE}=70-50 \mu \mathrm{s}$

Second $\mathrm{TE}=4.6 \mathrm{~ms}, \mathrm{FA}=4^{\circ}-9^{\circ}$

Spatial resolution $=1.3-1.04 \mathrm{~mm}$

$\mathrm{TA}=5-10 \mathrm{~min}$. [27]

FOV $=4 \mathrm{~mm}$, slice thickness $=3 \mathrm{~mm}$

Gradient amplitude $=40 \mathrm{mT} / \mathrm{m}$

Slew rate $=150 \mathrm{mT} / \mathrm{m} / \mathrm{s}$, Bandwidth $=62.5 \mathrm{kHz}$

$\mathrm{TR}=100 \mathrm{~ms}, \mathrm{TE}=8 \mu \mathrm{s}, \mathrm{FA}=60^{\circ}$,

Spatial resolution $=1.35 \times 1.35 \times 1.35 \mathrm{~mm}^{3}$

MT $=$ Fermi pulse $8 \mathrm{~ms}$, spectral bandwidth $=0.8 \mathrm{kHz}$

$\mathrm{TA}=12 \min$. [32]

$\mathrm{FOV}=400-240 \mathrm{~mm}$

Gradient amplitude $=45 \mathrm{mT} / \mathrm{m}$

Slew rate $=200 \mathrm{mT} / \mathrm{m} / \mathrm{ms}$, bandwidth $= \pm 250 \mathrm{kHz}$

$\mathrm{TR}=1.6 \mathrm{~ms}, \mathrm{TE}=286 \mu \mathrm{s}$

$\mathrm{FA}=6^{\circ}, \mathrm{RF}$ pulse $=24 \mu \mathrm{s}$

$\mathrm{TA}=5.17 \mathrm{~min}$. [33]

FOV $=340 \times 340 \mathrm{~mm}^{2}$, section thickness $=3 \mathrm{~mm}$

Bandwidth $=250 \mathrm{kHz}$

$\mathrm{TR}=116.7 \mathrm{~ms}, \mathrm{TI}=50 \mu \mathrm{s}$

$\mathrm{TE}=0.032,0.2,0.4,0.8 \mathrm{~ms}$

$\mathrm{TA}=4-10 \mathrm{~min}[30]$

$\mathrm{TA}=4.5 \mathrm{~min}$ for each dataset. [34]

$\mathrm{FOV}=530-240 \mathrm{~mm}$, slice thickness $=2-3 \mathrm{~mm}$

Gradient amplitude $=22.2-24.5 \mathrm{mT} / \mathrm{m}$

Slew rate $=200 \mathrm{mT} / \mathrm{m} / \mathrm{ms}$, bandwidth $=500-250 \mathrm{kHz}$

$\mathrm{TR}=471-793 \mathrm{~ms}, \mathrm{TE}=0$

$\mathrm{FA}=2.2^{\circ}, \mathrm{RF}$ hard pulse $=3 \mu \mathrm{s}$

Isotropic spatial resolution $=1.66-0.83 \mathrm{~mm}$

$\mathrm{TA}=2.31-3.12 \mathrm{~min}$. [35]

$\mathrm{FOV}=220-260 \mathrm{~mm}$

$\mathrm{TR}=10 \mathrm{~ms}, \mathrm{TE}=0$

$\mathrm{FA}=1.2^{\circ}$, bandwidth $=62.5 \mathrm{kHz}$ 
Table 2 (continued)

\begin{tabular}{|c|c|}
\hline Name of the sequence & MRI settings \\
\hline \multirow{6}{*}{ ZTE-PETRA (ZTE-pointwise encoding time reduction with radial acquisition) } & Isotropic spatial resolution $=1.35-0.85 \mathrm{~mm}^{3}$ \\
\hline & $\mathrm{TA}=2.53-6.12 \min [36]$ \\
\hline & $\mathrm{TR}=10 \mathrm{~ms}, \mathrm{TE}=85 \mu \mathrm{s}$ \\
\hline & $\mathrm{FA}=5^{\circ}, \mathrm{RF}$ pulse $=20 \mu \mathrm{s}$ \\
\hline & Spatial resolution $=1.17 \times 1.17 \times 1.17 \mathrm{~mm}^{3}$ \\
\hline & Bandwidth $=62.6 \mathrm{kHz}(=5 \mu$ s dwell time $)[37]$ \\
\hline \multirow[t]{6}{*}{ MT-ZTE (magnetization transfer ZTE) } & FOV $=45 \mathrm{~mm}$, isotropic spatial resolution $=0.35 \mathrm{~mm}^{3}$ \\
\hline & Gradient amplitude $=370 \mathrm{mT} / \mathrm{m}$ \\
\hline & Slew rate $=3375 \mathrm{~T} / \mathrm{m} / \mathrm{ms}$, bandwidth $=178 \mathrm{kHz}$ \\
\hline & $\mathrm{TR}=1 \mathrm{~ms}, \mathrm{TE}=0 \mu \mathrm{s}, \mathrm{FA}=3.7^{\circ}$ \\
\hline & $\mathrm{MT}=$ Gaussian pulse $10 \mathrm{~ms}$ \\
\hline & $\mathrm{TA}=3.16 \mathrm{~min}[38]$ \\
\hline
\end{tabular}

techniques, i.e., continuous wave $(\mathrm{CW})$, pulsed, and stochastic. Specifically, SWIFT is based on a swept RF excitation, similar to the CW NMR but with a faster rate, where the signal is acquired as a function of time, like in the pulsed NMR, and extracted by using the correlation method as done in the stochastic NMR [44-46]. This method leads to an MRI sequence that allows a nearly simultaneous excitation and acquisition scheme, hence suitable for the detection of ultrashort $T_{2}$ components. The scheme for SWIFT uses sequences of RF pulses with a specific $\left(T_{p}\right)$ duration in the order of milliseconds. Each pulse is divided into $N$ segments, having the RF pulse on for a $\tau_{\mathrm{p}}$ duration after a delay with the RF off. The acquisition is performed at $\tau_{\mathrm{a}}$ after the pulse segment (Fig. 4). In this way, a full set of frequency-encoding projections are firstly acquired and then reconstructed by using a 3D back-projection algorithm or gridding. The imaging process is then performed by using a cross-correlation method. However, this time-shared method, or gapped method, is limited by the time needed for the intermediate passage between each $N$ segment. Such restriction compromises the SNR and the resolution of the images [43]. Several improvements of the SWIFT sequence have been already proposed by Idiyatullin et al., such as a continuous SWIFT acquisition mode (cSWIFT), a multiple excitation bands approach (MB-SWIFT), and a gradientmodulated SWIFT (GM-SWIFT), which are able to overcome the hardware limitations and to reduce the SAR and the acquisition time [47-49].

\section{Anatomical Considerations on Hard Tissues}

Hard tissues comprise all the tissues that show a mineralized component in their extracellular matrix, such as bone and teeth. The ratio of the mineral phase is not only different for each tissue but can vary with age, sex, gender, and site [50]. Such tissue heterogeneity results in different $T_{2}$ properties according to the amount of available free water (Table 1). In the following paragraphs, a general overview of the specific chemical components of bone and teeth is provided.

\section{Bone}

Bone is a mineralized tissue that performs several functions in the body. Bone protects the vital organs, provides sites for

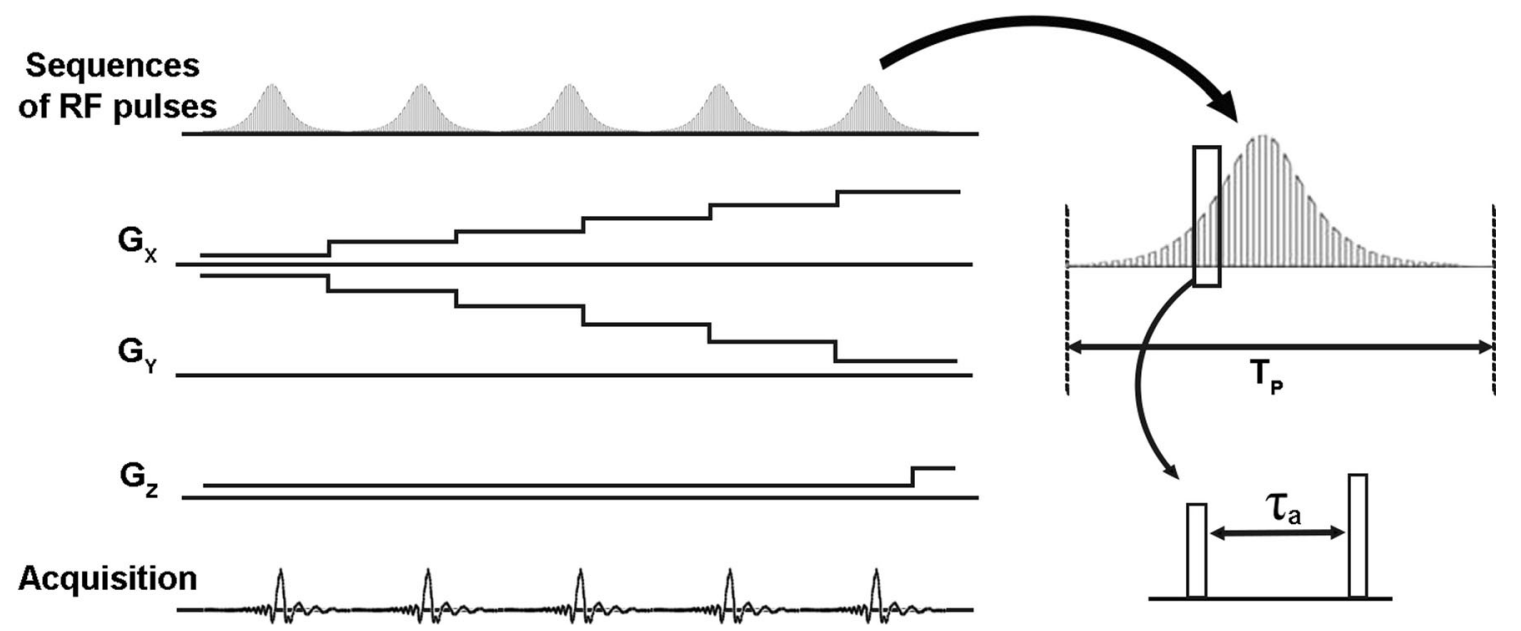

Fig. 4. Schematic representation of a basic SWIFT sequence. Note that SWIFT uses sequences of RF pulses each of them having $T_{p}$ duration in the range of milliseconds. The pulse is divided into $N$ segments reported on the left of the figure. Data sampling is performed at $\mathrm{T}_{\mathrm{a}}$ time after each segment. Adapted from [42]. 
muscle attachment to allow for motion and locomotion, produces the blood cells, and serves as a reservoir for several important ions (e.g., calcium and phosphate). The adult human skeleton consists of two main components: compact bone ( $\sim 80 \%$, also called cortical bone) and trabecular bone ( $\sim 20 \%$, also called cancellous or spongy bone). The ratio of cortical and trabecular bone is different depending on the different locations in the skeleton. As the name implies, compact bone shows a dense structure that is almost solid (i.e., $10 \%$ or less in porosity) and consists of parallel cylindrical units called osteons (or Haversian systems). Compact bone is present at the outer areas of long bone like femur and tibia, small bones like wrist and ankle, and flat bones like skull vault and other irregular bones. Trabecular bone is less dense than cortical bone, presents higher porosity usually between 50 and $90 \%$, and is located near the ends of long and small bones and in between the surfaces of flat bones. The outer surface of the bone is covered by a connective tissue, named the periosteum, which plays an important role in the skeletal development and bone healing (Fig. 5) [51-53].

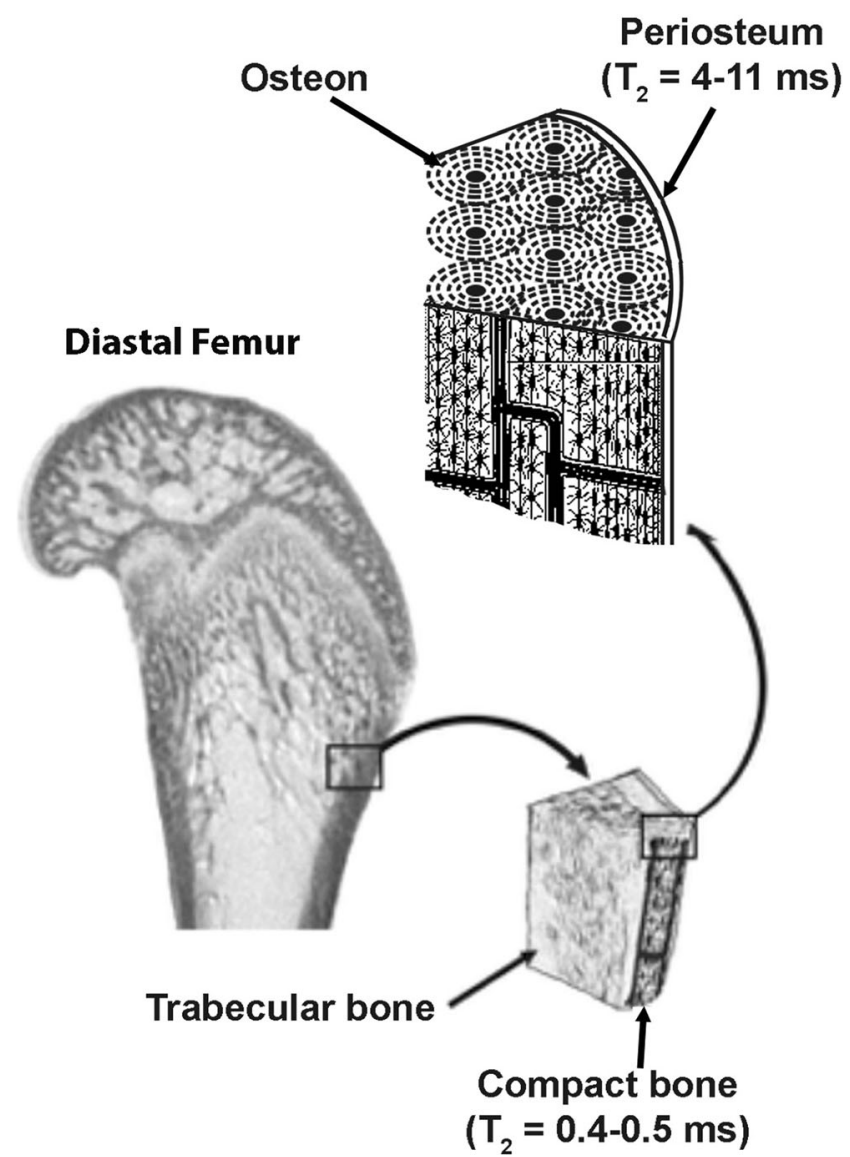

Fig. 5. Schematic representation of long bone morphology. From the outside towards the inside it is possible to distinguish the periosteum, compact bone (that consists of osteons) and the trabecular bone. Note that each tissue has different $T_{2}$ values according to his composition. $T_{2}$ values reported in the figure are measured on a $1.5 \mathrm{~T} \mathrm{MRI}$ system.
The mineral component of the bone consists of hydroxyapatite (HA). Depending on the site, the mineral component of most bones represents $60 \%$ to $70 \%$ of the total dry weight, with an exception of the ossicles in the ear that show up to $98 \%$ of mineral content. The remained component of the bone consists of an organic phase (20-30\%) and water $(10-15 \%)$. The main component of the organic phase is collagen type I (about $90 \%$ ), which is stiffened with the mineral phase, while non-collagenous proteins, lipids, and water are present in minor amount, i.e., $5 \%, 3 \%$, and $2 \%$ respectively [54-56].

Water content into the bone is found to be in three different forms. Firstly, water can be associated with the mineral phase; secondly, water can be associated with the organic collagen phase; thirdly, there is free bulk water located in the pores of the mineral phase $[57,58]$. Naturally, the occurrence of both freely and tightly bound water results in two major relaxation components, which decay at different rate. Protons associated with the mineral phase and the organic phase are decaying quickly (i.e., $\mathrm{T}_{2}<$ $11.7 \mu \mathrm{s}$, and $\mathrm{T}_{2}=320 \mu \mathrm{s}$, respectively), while bulk water decays slowly $\left(\mathrm{T}_{2}=2.28 \mathrm{~ms}\right)$ as measured on a $3 \mathrm{~T}$ MRI system [59-61].

\section{Teeth}

Mammalian teeth consist of four main tissues: enamel, dentin, cementum, and pulp. Enamel, dentin, and cementum represent three differently mineralized tissues that are tightly attached to each other, while the pulp is the only soft tissue of the tooth (Fig. 6). The enamel is a highly mineralized structure (up to $96 \%$ ) forming the outer shell of the crown and is mechanically the hardest substance in the body. The remained $4 \%$ consists of water and other organic proteins called amelogenin, ameloblastins, and enamelins. The dentin is formed by $70 \%$ mineral phase, $20 \%$ of organic phase, mainly collagen type I, and $10 \%$ water. The cementum is a thin layer present between dental root and the periodontium. The thickness of the cementum is raging from 50 to $1500 \mu \mathrm{m}$ depending on different locations and teeth. Cementum consists of $45-50 \%$ of HA as inorganic phase, $50-55 \%$ organic phase (mainly collagen type I), and for the rest of water [62-67]. Because of very low water content relaxation times for dentin and enamel are very short, i.e., $\mathrm{T}_{2}<1 \mathrm{~ms}$ and $70 \mu \mathrm{s}$, respectively (data measured on a $1.5 \mathrm{~T}$ system) [68].

\section{Ultrashort Echo Time Sequences for Bone Imaging}

Conventional UTE (CUTE) as well as optimized UTE sequences were firstly used to image human osseous tissues (e.g., periosteum, knee, lumbar spine, cortical bone in the tibia) by Bydder's group (Table 2) $[28,29]$. The implementations of the CUTE sequence were based on two different 


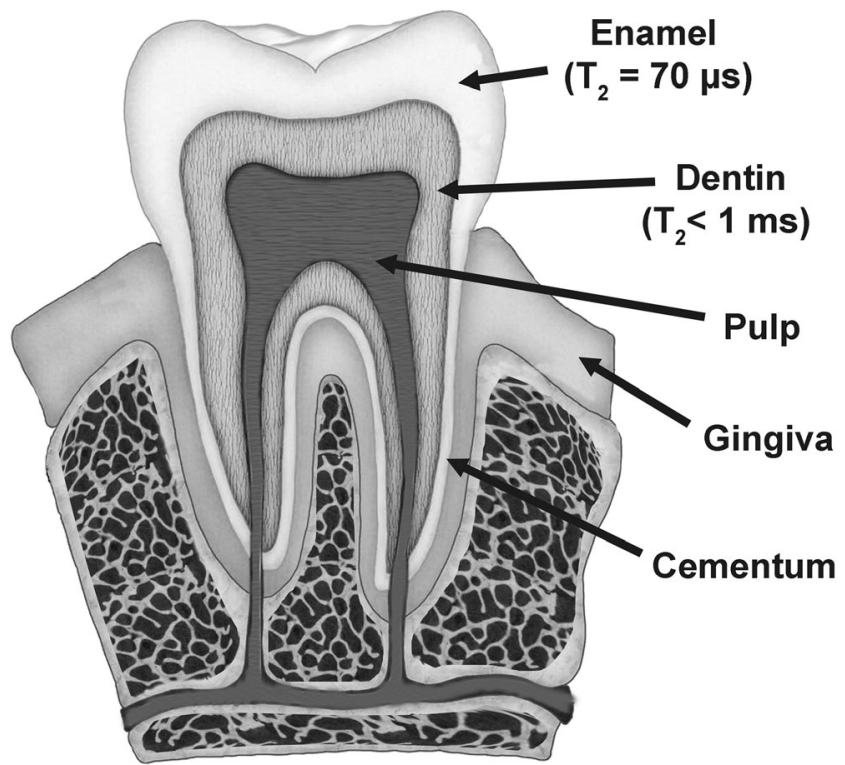

Fig. 6. Schematic representation of human molar anatomy. From the outside to the inside it is possible to distinguish enamel, dentin, and dental pulp. $T_{2}$ values reported in the figure are measured on a $1.5 \mathrm{~T}$ MRI system. Adapted from www.charlesfamilydental.com.

strategies: reduction of the signal from long- $\mathrm{T}_{2}$ components and fat suppression. Through the reduction of the signal from long- $\mathrm{T}_{2}$ components an increase of the image contrast of the short- $\mathrm{T}_{2}$ components was obtained, while fat suppression allowed a reduction of the background signal. Based on these strategies different optimized UTE sequences were developed, such as long- $\mathrm{T}_{2}$ suppression UTE (LUTE), fat suppressed UTE (FUTE), short inversion time (TI) with UTE (STUTE), and medium TI with UTE (MUTE, Table 2). Among them, FUTE was found to be the most promising sequence as it was able to show contrast of the tibial periosteum and of the cortex in healthy patients. However, the signal from the cortical bone, which was associated to the collagen type I and the bound water, was found to decrease with the increase of the distance of the tissue from the MRI coil [29].

A different approach to allow UTE imaging in clinical applications was based on the subtraction of subsequent UTE images acquired with longer echo times. The subtracted UTE images resulted in a reduced signal from the tissue with long $T_{2}$ and highlighted the signal contrast from the short $T_{2}$ tissues. In this way it was possible to obtain high signal to noise images of the periosteum and of the bone at different locations in human volunteer (e.g., tibia, fibula, and spine). Interestingly, the thickness of the periosteum obtained from MRI was reported being consistent with the standard anatomical descriptions [69]. Furthermore, this subtraction method was used to obtain a positive signal from the cortical bone with higher conspicuity. Specifically, subtracted images acquired with FUTE sequence was used to show callus formation in a fractured tibia of a 22-year-old male patient 3 weeks after the injury, as well as the difference in cortical bone density between healthy and osteoporotic patients. On the other hand, subtracted images acquired with CUTE showed new bone formation occurring in 32-year-old female patients after 4 years from a tibia injury [70]. Nevertheless, these modified UTE sequences were subject to susceptibility and gradient distortion artifacts. Suppression of the signal from long- $\mathrm{T}_{2}$ and fat components was also evaluated by combining the UTE sequence with an off-resonance saturation contrast (UTE-OSC, Table 2). The long $\mathrm{T}_{2}$ components are minimally affected by the off-resonance saturation pulse; hence, the subtraction of UTE images with and without OSC resulted in water and fat suppression that selectively depicted the short $\mathrm{T}_{2}$ components [30].

UTE spectroscopic imaging methods (UTESI) were developed based on highly undersampled interleaved projection reconstructions with multi-echo time sequences (Table 2) [71, 72]. Using the UTESI sequence, it was possible to achieve high spatial resolution spectroscopic images of the cortical bone in the order of $0.08-0.27 \mathrm{~mm}^{3}$, which is higher than the conventional spectroscopic techniques (in the order of $\mathrm{mm}^{3}$ ). The success of this spectroscopic technique arises from three main factors: 1) a minimal TE of $8 \mu \mathrm{s}$ that was achieved through the combination of a variable-rate selective excitation (VERSE), a radial ramp selection, and a fast transmit/receive switch; 2) an interleaved variable TE UTE acquisition that significantly improved the spatial resolution; 3) suppression of long $T_{2}$ components from muscle and fat.

Further improvements of UTE imaging methods consisted in a dual adiabatic inversion recovery UTE sequence (DIR-UTE) and an adiabatic inversion recovery UTE sequence (IR-UTE), which were tested for cortical bone (Table 2). DIR-UTE method was able to suppress long- $\mathrm{T}_{2}$ component and the signal from the surrounding fat and muscle, displaying the distal tibia of healthy volunteer with high contrast. However, DIR-UTE is a 2D technique, hence subject to partial-volume effect when tiny structures $(<$ $0.1 \mathrm{~mm}$ ) need to be images [73]. IR-UTE method provided excellent qualitative and quantitative depiction of the bone in vitro and in vivo, based on a robust long $\mathrm{T}_{2}$ species suppression achieved using an inversion recovery and a short TR (Table 2). In comparison with a standard UTE sequence, IR-UTE technique provided lower SNR but higher CNR [31].

Importantly, the possibility to quantify the proton density in hard tissues through UTE-based approaches opened a new scenario for MRI. In fact, UTE- and ZTE-based MRI could be used as a screening tool for the detection of bone diseases related to bone pore size and water content changes (e.g., in osteoporotic conditions), as well as for understanding the healthy condition of the bone. It is known that a deficit of bone mineral content is related to an increase in water content; an increase in free bulk porous water corresponds to increased bone porosity; tightly-bound water is associated with the mineral content [74]. Gravimetric 
studies, ${ }^{1} \mathrm{H}$ NMR, and three-point bending test performed on tibiae harvested from healthy and phosphorous-deficient rabbits, have proven that bound water is associated with bone strength and toughness, while free water is associated with the elasticity modulus of bone. Therefore, mineral features and water content can be related to the bone biomechanical properties, and to the risk of bone fractures [74].

Chang et al. combined the UTE sequence with the magnetization transfer (MT), which is an indirect imaging method that allows a quantitative and qualitative assessment of protons with extremely fast relaxation [32]. UTE-MT imaging provided accurate information about cortical bone tissue properties by using a whole-body clinical 3 T MRI scanner in only $2 \mathrm{~min}$ acquisition time. The off-resonance saturation ratio (OSR) measured through UTE-MT method on human cadaveric femora and tibia correlates with the bone porosity measured via $\mu \mathrm{CT}$ and the mechanical properties, such as Young's modulus and yield stress, measured through a four-point bending test. Specifically, a moderate negative correlation between the OSR and the cortical porosity $\left(R^{2}=0.51\right)$, and a positive correlation between OSR and both Young's modulus $\left(R^{2}=0.12\right)$ and yield stress $\left(R^{2}=0.30\right)$, were observed [32]. Horch et al. associated a preexisting UTE pulses with a double adiabatic full passage (DAFP) sequence and an adiabatic inversion recovery (AIR) for the detection of the pore and bound water, respectively. These sequences were used to acquire human cadaveric femora on a $4.7 \mathrm{~T}$ system. The estimated water content was correlated to the mechanical properties, such as Young's modulus, yield stress, peak stress, and toughness to failure measured through three-point bending tests. Pearson's correlation values between DAFP- and AIR-UTE method and the various mechanical properties were ranging between 0.35 and 0.69 , hence providing a proof-of-concept that these UTE-based strategies can be used for the prediction of bone fractures [75]. Afterwards, the same authors translated the DAFP and AIR UTE protocols for the quantitative mapping of bound and porous water in radius and tibia of six healthy volunteers on a $3 \mathrm{~T}$ MRI clinical system. The outcomes of the study showed that the bound water concentration was approximately 28 and $35 \mathrm{~mol}{ }^{1} \mathrm{H} / 1$ of bone, while the porous water was 7 and $6 \mathrm{~mol}{ }^{1} \mathrm{H} / \mathrm{l}$ of bone, for tibia and radius respectively. These findings corroborated with the values reported in previous observations in femoral specimens [76]. Recently, a few more UTE-based methods to detect water content in vivo with more accuracy and precision have been proposed, such as IR-UTE, 3D IR-UTE, and UTE sequence associated with a numerical-based algorithm [77-79]. However, the statistical correlation of these methodologies with the mechanical properties remains unexplored. Furthermore, water molecules bound to the collagen matrix or to the crystal phase are decaying really fast $(<10 \mu \mathrm{s})$ and their detection is still challenging even by using the most advanced UTE sequence.
The feasibility to use 3D UTE-MRI for the depiction of the mandibular condyle morphology, which is indicative of degenerative joint diseases, was investigated on human cadaveric specimens and compared with measurements performed via $\mu \mathrm{CT}$. UTE-MRI was able to show the contour of the condyle cortical bone and the associated cartilage, which was not visible in $\mu \mathrm{CT}$ images. MRI reported accurate information, with an isotropic voxel size of $100 \mu \mathrm{m}$, including joint surface curvature, incongruity, as well as cartilage thickness [80]. In 2014, Serai et al. proved the technical feasibility of UTE-MRI in pediatric musculoskeleton at a clinical $1.5 \mathrm{~T}$ system with less than $5 \mathrm{~min} \mathrm{TA}$, supporting its beneficial use for the evaluation of bone pathology, such as irregular ossification at the weightbearing site of the femoral condyle [81].

Another challenge in MR imaging of hard tissues is to image bone structures in technically difficult areas. For instance, MR imaging of the hip is considered technically challenging due to the presence of a thin cortex, the requirement of a robust suppression of the surrounding soft tissues, and the lack of commercially available dedicated coils. A 3D UTE-Cones sequence, which employs a hard RF pulse for non-selective signal excitation followed by a 3D cones trajectory for $\mathrm{k}$-space sampling, allowed time-efficient sampling with a minimal nominal TE of $32 \mu \mathrm{s}$. The 3D UTE-Cones was combined either with an adiabatic inversion recovery (3D IR-UTE-Cones) or a dual inversion recovery (3D DIR-UTE-Cones) preparation pulse. Such techniques were used for the visualization of the cortical bone in the hip, tibia, knee, and ankle, and for the quantification of the associated $\mathrm{T}_{2}{ }^{*}$ values (Table 2) $[34,82]$. Furthermore, the combined 3D UTE-Cones sequence with a multi-spoke per MT preparation and with a modified rectangular pulse (RP) model allowed for a fast-volumetric quantification of the water content in short $T_{2}$ tissues by using a clinical $3 \mathrm{~T}$ whole-body scanner [83].

\section{P-31 UTE for Bone Imaging}

As HA is the main component of bone, P-31 MR imaging gained attention to obtain information about the bone mineral density. However, this technique is still challenged by the fact that the $\mathrm{T}_{2}{ }^{*}$ of the cortical bone is very short (i.e., $179 \mu \mathrm{s}$ at $1.5 \mathrm{~T}$ ) and the $\mathrm{T}_{1}$ is very long (i.e., $10.1 \mathrm{~s}$ at $1.5 \mathrm{~T}$ ). The first UTE MRI of P-31 was performed in 2004 by Robson et al. on seven healthy human patients [84]. The authors reported a P-31 based image of the tibial cortical bone with pixel dimension of $0.3 \mathrm{~mm}$ that corresponded to $2.9 \mathrm{~mm}$ true resolution. The $\mathrm{T}_{2}{ }^{*}$ and $\mathrm{T}_{1}$ for cortical bone were measured and the reported values were $207 \pm 12 \mu \mathrm{s}$ and $8.6 \pm 3.0 \mathrm{~s}$, respectively. P-31 MRI was also performed on trabecular bone, although a reduced SNR was observed due to the lower P-31 concentration per unit [84]. Afterwards, a P-31 quadrature low-pass birdcage coil, which was able to provide $10 \mu \mathrm{s}$ hard pulses for a $10^{\circ}$ flip angle, was built and 
tested to image human wrist on a $3 \mathrm{~T}$ clinical system. The delay of transmit/receive switch was reduced through technical modifications of the circuit diode that led to a switching speed in the order of nanoseconds. In this way, 3D P-31 based images of the human wrist with a resolution of $3.5 \mathrm{~mm}$ and improved SNR were achieved in $37 \mathrm{~min}$ acquisition time [85].

Detection of P-31 content into bone tissue can be performed also with UTE-CSI method [86]. This approach is based on the minimization of the RF excitation as well as of the time delay between the end of the RF pulse and the start of the data acquisition. UTE-CSI is more sensitive to short $\mathrm{T}_{2}$ components and has been used to acquire the $\mathrm{P}-31$ signal from human tibia with an isotropic resolution of $5 \mathrm{~mm}$.

\section{Zero Echo Time Sequences for Bone Imaging}

ZTE MRI was also applied for bone tissues on a clinical scanner and improved simultaneously along with the development of UTE methods.

Water- and fat-suppressed proton projection MRI (WASPI) represents a type of zero echo time pulse that allowed to excite only short $\mathrm{T}_{2}^{*}$ components based on a $\mathrm{T}_{2}$ selective RF excitation method consisting of long-duration low-power rectangular RF pulses [87]. MRI-WASPI was used to image the solid matrix content of rat femora with a spatial resolution of $0.4 \mathrm{~mm}$, hence representing a useful tool for the quantification of the bone matrix density [88]. A further implementation of ZTE MRI for humans was reported in 2013 by Weiger et al. (Table 2) [35]. The authors reported the first 3D ZTE images of the human head, wrist, knee, and ankle on a $7 \mathrm{~T}$ human whole-body MRI system. The acquired images showed fine anatomical details with a well-delineated bone tissue interface, high SNR, and isotropic spatial resolution of $0.83 \mathrm{~mm}$ [35]. In addition, ZTE method was also used on a $7 \mathrm{~T} \mu \mathrm{MRI}$ system to image trabecular microstructures in bovine bone samples, and the images were compared with $\mu \mathrm{CT}$ results. With respective imaging resolutions of $56 \mu \mathrm{m}$ and $14.8 \mu \mathrm{m}$ for ZTE and $\mu \mathrm{CT}$ acquisitions, the trabecular micro-architecture was shown with excellent agreement on both modalities. Furthermore, the assessed bone volume fraction resulted in similar values, i.e,. 0.34 , and 0.36 , for both ZTE imaging and $\mu \mathrm{CT}$ [89]. Afterwards, a rotating ultrafast imaging sequence (RUFIS) type of ZTE imaging (ZTE-RUFIS) was developed using a non-selective hard pulse excitation followed by a 3D center-out radial sampling (Table 2). With ZTE-RUFIS sequence image acquisition started immediately leading to a nominal TE equal to zero. Furthermore, by using minimal gradient switching in between repetitions and short RF pulses, a robust and fast method with more efficient SNR was achieved. Such ZTEbased method provided high-resolution pictures of the cranium, facial skeleton, and cervical vertebrae of human volunteers. MRI acquisitions depicted anatomical details equivalent to the $\mathrm{CT}$ acquisitions obtained in a PET/CT scanner [36].

Additionally, ZTE technique was associated with a MT method and tested for the imaging of the cortical bone composition in mice on a $4.7 \mathrm{~T}$ system (Table 2). Relaxation time properties of the femoral diaphysis that were based on MT-ZTE acquisitions were reported, and the values were $1107 \pm 203 \mathrm{~ms}$ for $\mathrm{T} 1,12.5 \pm 2.0 \mu \mathrm{s}$ for $\mathrm{T} 2$, and $563 \pm 75 \mu \mathrm{s}$ for $\mathrm{T}_{2} *$, which resulted to be higher when compared to previous studies. These differences were not only ascribed to a difference in magnetic field strength that was different when compared to other studies, but also to the higher sensitivity of the MT-based approach [38].

A in vivo comparison study between UTE and ZTE methods was performed on a $7 \mathrm{~T}$ system [90]. After MRI acquisition of the bone in the brain, ankle, and knee of human volunteers the results dealing with the imaging quality, resolution capabilities, and off-resonance sensitivity were compared to each other. This study showed no differences in resolution capabilities and comparable image contrast and SNR for both UTE and ZTE images. Only subtle differences were found in the off-resonance response, due to the difference in k-space sampling for these two MRI techniques. ZTE acquisitions showed increased blurring around the skull, as well as signal dropout artifacts in proximity of the edge of the field of view, while UTE methods showed more flexibility in imaging volume selection resulting more adequate for clinical applications [90].

\section{P-31 ZTE for Bone Imaging}

The assessment of the mineral bone composition through a ${ }^{31}$ P-ZTE-PETRA acquisition has been tried on human cadaveric tibia specimens. The obtained mean level of the bone mineral P-31 content was $6.7 \pm 1.2 \mathrm{~mol} / \mathrm{l}$, and the values were positively correlated to the bone density measured by $\mu \mathrm{CT}\left(R^{2}=0.46\right)$. Furthermore, P-31 $\mathrm{T}_{1}$ relaxation time assessments showed a positive correlation with the bone density measured via $\mu \mathrm{CT}\left(\mathrm{R}^{2}=0.62\right)$ and a negative correlation with the porosity $\left(\mathrm{R}^{2}=0.45\right)$ calculated from the water content. These findings showed that it is possible to associate a decrease in $\mathrm{P}-31 \mathrm{~T}_{1}$ with an increase in bone porosity. The rationale behind such association is that an increase in porosity lead to a loss of minerals from the bone matrix. Therefore, the remaining P-31 nucleus can interact with a greater number of protons resulting in a reduction of the ${ }^{31} \mathrm{P} \mathrm{T}_{1}$ value [91].

Recently, the same ${ }^{31}$ P-ZTE-PETRA method was used to image tibia of healthy volunteers. Bone mineral content estimated through P-31 MRI showed a strong positive correlation with bone mineral content assessed through high-resolution peripheral quantitative CT $\left(\mathrm{R}^{2}=0.96\right)$ [92]. 


\section{Ultrashort TE MR Imaging of Teeth}

The use of MRI in dentistry is continuously increasing. Dental tissues, however, show the shortest relaxation profile, making their imaging the toughest challenge for MRI. The first UTEMR image of teeth was acquired by Gatehouse et al. in 2003 [29] through FUTE method on a $1.5 \mathrm{~T}$ system. Afterwards, human volunteers were also scanned using a whole-body $3 \mathrm{~T}$ system with a total scanning time of $10 \mathrm{~min}$ [93]. The sagittal slice of the jaw acquired by UTE sequences with TE $=50 \mu \mathrm{s}$ provided a clear view of all the dental structures including enamel (Table 3). Subsequently, 3D-UTE sequence was used not only to image teeth but also to estimate the relative $\mathrm{T}_{2}{ }^{*}$ values, which could be correlated with the presence of dental caries $[94,96,97]$. In fact, the mineral breakdown caused by caries was found to lead to a gradual increase in $T_{2}$ value, depending on the extension of the lesion, hence supporting the use of UTE-based MRI as a feasible screening tool for the early detection of dental caries.

SWIFT sequences have shown the possibility to obtain simultaneous acquisition in vivo of both soft and hard dental tissues with high resolution and short acquisition time (Table 3) [94]. SWIFT-MRI acquisitions were performed on a $4 \mathrm{~T}$ system and with a custom-made one-side shielded coil, which was located between the cheek and the teeth. The shielded coil was able to minimize the signal from the surrounding soft tissue. Furthermore, to reduce artifacts associated with the patient motion, a single motion correction was performed by comparing 16 low-resolution images. Furthermore, SWIFT-MRI has been used for the ex vivo detection of cracks into human molars. The presence of higher water concentration into the cracks when compared to the surrounding dentin enables the detection of lesions up to $20 \mu \mathrm{m}$ in width [98].

High-resolution ZTE images of extracted teeth (i.e., incisors, canine, molars, and wisdom teeth) were made ex vivo using an $11.7 \mathrm{~T}$ MRI system. MR images of the teeth showed various dental caries and dental fillers, including amalgam and ceramic materials. Three-dimensional ZTE

Table 3. Ultrashort MRI sequences dental tissues

\begin{tabular}{ll}
\hline Name of the sequence & MRI settings \\
\hline UTE in teeth & FOV $=80 \mathrm{~mm}^{3}$ \\
& Gradient amplitude $=40 \mathrm{mT} / \mathrm{m}$ \\
& Slew rate $=200 \mathrm{~T} / \mathrm{m} / \mathrm{ms}$, Bandwidth $=357 \mathrm{kHz}$ \\
& $\mathrm{TR}=9.4 \mathrm{~ms}, \mathrm{TE}=50 \mu \mathrm{s}$ \\
& Isotropic spatial resolution $=250 \mu \mathrm{m}^{3}$ \\
& FA $=10^{\circ}, \mathrm{TA}=10 \mathrm{~min}[93]$ \\
& FOV $=110 \mathrm{~mm}, \mathrm{TR}=2.5 \mathrm{~ms}$ \\
SWIFT & Isotropic spatial resolution $=430 \mu \mathrm{m}^{3}$ \\
& $\mathrm{RF}$ pulse $=2 \mathrm{~ms}$, bandwidth $=62 \mathrm{kHz}$ \\
& FA $=8^{\circ}, \mathrm{TA}=10$ min $[94]$ \\
& FOV $=1.9 \times 1.9 \times 2.4 \mathrm{~mm}$ \\
& $\mathrm{TR}=1.0 \mathrm{~ms}, \mathrm{TE}=0, \mathrm{FA}=3^{\circ}$ \\
& Isotropic spatial resolution $=148 \times 148 \times 188 \mu \mathrm{m}$ \\
& Bandwidth $=200 \mathrm{kHz}$ \\
& $\mathrm{RF}$ pulse $=1 \mu \mathrm{Ts}, \mathrm{T} / \mathrm{R}$ switching $=4.5 \mu \mathrm{s}$ \\
& $\mathrm{TA}=6.55 \mathrm{~min}[95]$ \\
\hline
\end{tabular}

images with $148 \times 148 \times 188 \mu \mathrm{m}$ resolution were acquired in 6.55 min and compared with UTE-MRI and $\mu \mathrm{CT}$ acquisitions. ZTE-based MRI was able to highlight slight differences in dentin composition that were only barely or not recognizable at all by $\mu \mathrm{CT}$. Furthermore, ZTE-MRI showed signal variation around the pulp, which was not visible in $\mu \mathrm{CT}$, and local signal changes in the enamel and dentin. However, when compared to the ZTE-MRI, $\mu \mathrm{CT}$ showed better signal from enamel and dental calculus as present on the tooth surface. When UTE- and ZTE-based images were compared, ZTE imaging showed a better contrast of both dentin and enamel as also confirmed by the quantification of the SNR for each imaging modalities [95, 99].

Information about the mineral density of the teeth and of their major component (i.e., HA) was obtained by quantification of the phosphorous content. Extracted human molars were scanned on a 9.4 $\mathrm{T}$ system with a home-build double resonance (P-31 and $\mathrm{H}-1)$ probe through a ${ }^{31} \mathrm{P}-\mathrm{SWIFT}$ and ${ }^{31} \mathrm{P}$-ZTE sequence. These methods provided ${ }^{31} \mathrm{P}$-based images, which made it possible to distinguish the enamel from the dentin structures with a resolution of $0.5 \mathrm{~mm}$. When comparing the two MRI methods, the P-31 MRI images obtained through ${ }^{31} \mathrm{P}$-ZTE imaging showed better SNR (> $28 \%$ ) than ${ }^{31}$ P-SWIFT [100].

The lack of coils and powerful gradient in a whole-body MRI system is hampering the translation of ZTE-MRI into the clinic [101]. An intraoral MRI coil that can be placed between the maxillary and mandibular teeth has recently been proposed by Idiyatullin et al. [102]. The coil consisted of a single loop of $10 \mathrm{~mm}$ width and covered with sticky foam to be suitable for the adult maxillary arch. This coil was used for MRI acquisition of a human volunteer at a $4 \mathrm{~T}$ MRI scanner through a 3D radial SWIFT sequence. The intraoral coil showed high SNR and spatial resolution $\left(0.3 \mathrm{~mm}^{3}\right)$ compared to an extraoral coil. However, the main limitation of the intraoral coil was the lower SNR in proximity of the cusps of the teeth [91]. Ludwig et al. developed a wireless inductively-coupled intraoral coil consisting of two coaxial loops of 1.5 and $2 \mathrm{~cm}$ diameter. The coil was covered with a dental resin and adapted to the human mouth anatomy by a home-made dental cast [103]. The coil was used firstly ex vivo on a porcine mandible and then in vivo in a human volunteer on a $3 \mathrm{~T}$ MRI system. However, instead of an ultrashort TE sequence, a highresolution 3D-FLASH (fast low angle shot) was used for the image acquisitions. The coil showed improved SNR when compared to other dental coils described in the literature and displayed relevant anatomical details with an isotropic voxel size of $350 \mu \mathrm{m}$. The optimization and combination of the coil with ultrashort echo time sequences remain still unaccomplished [103].

\section{Ultrashort TE MR Imaging for Hard Tissue Substitutes and Biomaterials}

The development of MRI sequences that can detect short $T_{2}$ components widens the use of MRI also for artificial 
materials, as used in orthopedic and dental applications, like bone fillers and restorative materials [104]. Materials that are used for bone and dental application can be distinguished based on their degradation properties in degradable and nondegradable materials. Degradable materials, such as ceramics and certain polymers, have the property to be removed from the body through in vivo degradation, while non-degradable materials, such as metals and resins, are biologically compatible but mostly need to be removed from the body with an additional operation (e.g., metallic fracture stabilization plate) or left in situ (e.g., permanent dental fillers) $[105,106]$.

S. Emid and J.H.N. Creyghton [107] firstly proposed in 1985 a single-point imaging (SPI) method, also known as contrast time imaging (CTI), to study solid materials with very short $\mathrm{T}_{2}$ values $($ e.g., $>50 \mu \mathrm{s})$. SPI is a pure phaseencoding imaging method which uses a single data point in the k-space that is acquired after a short encoding time in presence of a gradient. Although SPI method has been widely used for special purposes, such as studying solids, removing susceptibility artifacts, and chemical shifts artifacts, long acquisition time was the main limitation. Conventional SPI has been recently implemented to enable continuous imaging with a more time-efficient acquisition (CSPI, continuous single-point imaging) [108].

In 2011 Springer et al. [109] proposed a modified Ernst equation and variable flip-angle method combined with a 3D-UTE sequence to visualize polymeric materials with a $3 \mathrm{~T}$ whole-body MRI scanner. The variable flip-angle method allowed for the $T_{1}$ quantification of the polymeric material within a reduced acquisition time. Although the exact materials composition was not described, the authors were able to estimate their relaxation properties, i.e., $\mathrm{T}_{1}=$ $223.1 \mathrm{~ms}$ and $\mathrm{T}_{2}{ }^{*}=0.295 \mathrm{~ms}$ [109]. Dental restoration materials, such as amalgam and ceramic inlays, inserted in human molars have been imaged with high-resolution ZTE sequence and compared with $\mu \mathrm{CT}$ acquisitions. Dental fillings caused image artifacts in both modalities depending on their compositions. Specifically, amalgam filling, which was used in a molar after endodontic treatment, caused a strong beam-hardening artifact compromising the $\mu \mathrm{CT}$ imaging. Differently, in ZTE images of amalgam filling the artifact was reduced and confined to the filling location allowing for better diagnosis [95]. MR imaging artifacts are very common also in presence of metallic implants, such as hip prosthesis, due to the large magnetic susceptibility differences between the implant and the tissue, which results in perturbation of $\mathrm{B}_{0}$. A fully phase-encoded UTE (UTEFPE) method has been proved to give distortion-free images near the metallic implants in human subjects and in about 5 min acquisition time (Table 2) [33].

A great variety of dental restoration materials have been imaged by UTE-MRI thus far. For all these compositions the relaxation profiles (i.e., $\mathrm{T}_{1}$ and $\mathrm{T}_{2}{ }^{*}$ values) were quantified and are available for further optimization of MRI sequences (Table 4) [110].
Biodegradable calcium phosphate-based (CPC) compositions have also been imaged by MRI. Sun et al. [111] investigated the MRI visual properties of a specific injectable CPC composition consisting of a mix of $68 \%$ alpha-tricalcium phosphate $(\alpha$-TCP), $8 \%$ dicalcium phosphate dehydrate, $4 \% \mathrm{HA}$, and $20 \%$ poly (lactic-co-glycolic acid) (PLGA). The CPC was first injected in vitro in a cylindrical defect created in bone blocks and subsequently implanted in vivo in cylindrical defects made in rat femora. The assessments were performed on an 11.7-T scanner with both UTE and ZTE sequences. Relaxation estimation for the CPC composition based on a 3D-UTE sequence showed a $\mathrm{T}_{2}{ }^{*}$ equal to $442 \mu \mathrm{s}$. This value was very close to the $\mathrm{T}_{2}{ }^{*}$ relaxation of the pig cortical bone (i.e., $597 \mu \mathrm{s}$ ), resulting in a similar MRI signal with both UTE and ZTE acquisition. This similarity in relaxation profiles hampered the identification of the CPC after implantation either in vitro or in vivo, which makes the use of MRI contrast agents a proper solution for the enhancement of the CPC signal [111]. Therefore, CPC has been combined with different contrast agents, such as superparamagnetic iron oxide particles (SPIO), gadolinium-based contrast agent (GBCA), and perfluorocarbons (PFC), aiming to a better visualization of the implant and a more precise in vivo follow-up [112-114].

CPC combined with a dedicated dual contrast agent (DCA) consisting of SPIO with a mean size of $200 \mathrm{~nm}$, and gold nanoparticles (AuNPs) with a mean size of $4 \mathrm{~nm}$ (respectively, as MRI and CT contrast agent) was imaged in vivo by ZTEMRI and CT after installation in rat femoral defects. Longitudinal ZTE acquisitions allowed the identification of the implanted CPC until 8 weeks post-implantation, while the CT contrast of the CPC was lost 4 weeks after implantation [99]. However, because of the strong susceptibility properties of the SPIO particles, a strong imaging artifact (named blooming effect) was observed on the ZTE-MR images. The blooming effect leads to an easy identification and localization of the implanted CPC but hampered the morphological analysis of the material [112]. Interestingly, blooming artifacts are also observed after ZTE-MRI acquisition of CPC combined with GBCA nanoparticles, which are known to show a $\mathrm{T}_{1}$-weigthed contrast agent [113]. The appearance of such artifacts could be partially ascribed to the high magnetic field strength (i.e., 11.7 T). Nevertheless, the use of fluorine-based contrast agents is considered as a possible solution to diminish imaging artifacts. Therefore, CPC was combined with polymeric nanoparticles containing PFC (i.e., perfluoro-15-crown-5-ether) and gold nanoparticles, respectively for ${ }^{19} \mathrm{~F}-\mathrm{MRI}$ and $\mathrm{CT}$ imaging. Fluorine-based ZTE-MRI of the labeled CPC implanted in rat femora permitted the fine visualization of the CPC shape and allowed the monitoring of the material degradation longitudinally up to 8 weeks post-implantation [114].

Another CPC composition, consisting of $59.1 \% \alpha$-TCP, $1.5 \%$ carboxymethylcellulose (CMC), and $39.4 \%$ cryogrinded PLGA, was used as a dental pulp capping agent in extracted human molars. The specimens were scanned on an 11.7-T scanner through a 3D-UTE and ZTE sequence. This 
Table 4.. $\mathrm{T}_{1}$ and $\mathrm{T}_{2}{ }^{*}$ of most common dental fillers measured at $3 \mathrm{~T}$. Adapted from [13, 110-112]

\begin{tabular}{lll}
\hline Material & $\mathrm{T}_{1}$ & $\mathrm{~T}_{2}{ }^{*}$ \\
\hline Methacrylate resins & $207 \mathrm{~ms}$ & $235 \mu \mathrm{s}$ \\
Triethylene glycol dimethacrylate & $28 \mathrm{~ms}$ & $180 \mu \mathrm{s}$ \\
Methacrylate-based cement & $214 \mathrm{~ms}$ & $106 \mu \mathrm{s}$ \\
Zinc phosphate cement & $30 \mathrm{~ms}$ & $40 \mu \mathrm{s}$ \\
2,2 Bis [4-(2-hydroxy-3-methacryloyloxypropoxy)-phenyl] & $159 \mathrm{~ms}$ & $96 \mu \mathrm{s}$ \\
Urethandimethacrylat & $227 \mathrm{~ms}$ & $337 \mu \mathrm{s}$ \\
Eugenol-free polycyarboxylate-based cement & $190 \mathrm{~ms}$ & $113 \mu \mathrm{s}$ \\
Hydroethyl dimethacrylate & $295 \mathrm{~ms}$ & $178 \mu \mathrm{s}$ \\
Resin-reinforced, chemically curing glaspolyalkenoate cement & $153 \mathrm{~ms}$ & $600 \mu \mathrm{s}$ \\
Hydroxyapatite & - & $1 \mu \mathrm{s}^{\#}$ \\
CPC compositions & $520-1000 \mathrm{~ms}^{\dagger}$ & $270-450 \mu \mathrm{s}^{\dagger}$ \\
\hline
\end{tabular}

${ }^{\#}$ Means $\mathrm{T}_{2}{ }^{*}$ measure at $1.5 \mathrm{~T}$

${ }^{\dagger}$ Measured on a $11.7 \mathrm{~T}$

specific CPC reported a $\mathrm{T}_{2}{ }^{*}$ equal to $273 \mu \mathrm{s}$, which was lower than the $\mathrm{T}_{2}{ }^{*}$ from human dentin (i.e., $\mathrm{T}_{2}{ }^{*}=476 \mu \mathrm{s}$ ). Therefore, such a CPC can be distinguished from dentin on the ZTE acquisition (Fig. 7). Also, relaxation studies were performed on the CPC before and after 7 weeks implantation in goat incisors. A lower $\mathrm{T}_{1}$ value was found for the CPC composition after the implantation in vivo, i.e., $742 \mathrm{~ms}$ versus $1008 \mathrm{~ms}$ after and before the in vivo implantation, respectively. These results suggested the feasibility to use

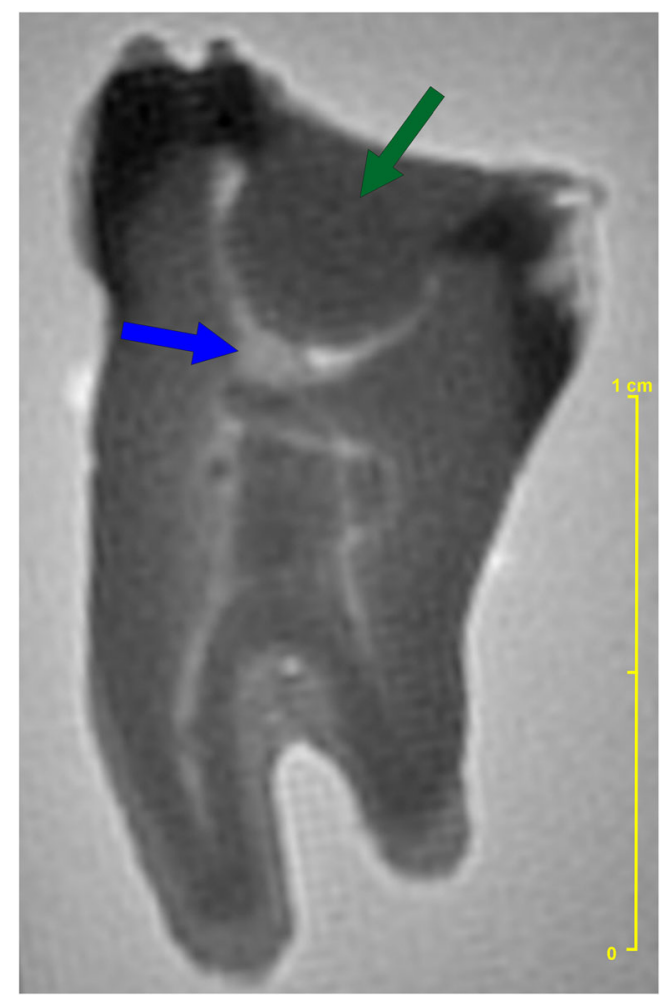

Fig. 7. ZTE-based MR image of human lower wisdom molar, which underwent pulp capping treatment with CPC. The following settings were used for the acquisition: $T R=2 \mathrm{~ms}$, $\mathrm{TE}=0, \mathrm{FA}=3^{\circ}, \mathrm{FOV}=4 \mathrm{~cm}$, matrix $=256 \times 256 \times 256, \mathrm{TA}=$ 13.46 min. Blue arrow indicates the applied CPC, while green arrow indicates glass ionomer restoration material. Image provided by the authors. the relaxation properties of the $\mathrm{CPC}$ to follow its degradation in vivo [115].

\section{Conclusions}

MRI sequences for the imaging of hard tissues (e.g., bone and teeth) and biomaterials used for restoration of such tissues are becoming more and more advanced. The huge potential of ultrashort TE MRI is evident, not only for the morphological high-resolution 3D reconstruction of bone and dental structures, but also for the early detection of bone and dental diseases. By using ultrashort TE MRI it is possible to obtain information about the status of a bone pathological condition. Moreover, MRI is considered a very promising screening tool in dentistry not only because of the lack of radiation, but also because of the simultaneous multiplanar imaging of soft and hard tissues as well as the ability to detect demineralization and dental caries [116].

However, many challenges still need to be solved before such MRI methods will be accessible to a wider patient population. While issues with hardware systems and fast transmit/receive switches can be solved in a relatively easy way, the need for high gradient performance remains still a challenge. One approach to image short $T_{2}$ component could be to use conventional MRI sequences and reducing the duration of the RF pulse to a value comparable with $T_{2}$ and using a readout gradient with much shorter time than the $T_{2}$. This approach is feasible in small-bore system but not suitable with whole-bore equipment. This is due to technical difficulty to build high-performing gradients (e.g., peak $40 \mathrm{~T} / \mathrm{m}$ and slew rate of $2 \mathrm{~T} / \mathrm{m} / \mathrm{ms}$ ) and RF systems capable to generate $10 \mu \mathrm{s} 180^{\circ}$ pulse (i.e., 7 $500 \mathrm{~kW} \mathrm{RF}$ amplified peak power) [14]. Furthermore, RF coils induce an electric field that results in deposition of energy into tissue in the form of heat. Such phenomenon can cause serious tissue damage especially in case of presence of metallic implants. Specific adsorption rate (SAR) limits have been set by regulations and are limiting the possibility to use higherperforming gradients $[18,117]$. To date, safety regulations limit the maximum gradient switching to $<20 \mathrm{~T} / \mathrm{m} / \mathrm{s}$, while $\mathrm{RF}$ excitation pulses are limited to $<4 \mathrm{~W} / \mathrm{kg}$ [14]. However, 
it is important to mention that UTE sequences have less SAR limitations when compared to other ultrashort echo time techniques, such as ZTE and SWIFT, where RF is applied simultaneously with encoding gradients. Furthermore, the requirement of appropriate software, which allows for qualitative and quantitative analysis, also needs to be considered as not all MRI manufacturing companies updated these recently developed sequences [16]. Finally, the extensive costs for MRI machines and their maintenance still hamper a global spreading of such imaging tools, especially in dentistry. The development of a relatively "cheap" MRI system is necessary. This review reported many studies that can be used as a proof-of-concept for the translation of MRI to dentistry. Therefore, the next step will be the refinement of the available technologies to make them suitable for dental applications, while the use of short-bore systems and of low magnetic fields relying on the prepolarization MRI concept can be suggested as a possible solution to reduce the manufacturing costs $[118,119]$.

In summary, ultrashort $\mathrm{TE}$ sequences represent an applicable MRI tool that allows quantitative and qualitative assessment of bone, teeth and solid-like biomaterials. Their clinical translation is an ongoing occurring process especially in the orthopedic field, while still many efforts need to be done in dental MR imaging. The use of biomaterials for bone and dental repair is well established in the clinic, which warrants the investigation of MRI sequences for their screening.

Acknowledgements. The authors like to thank Prof. Arend Heerschap for the scientific support and all the teaching.

Funding Information. The researches leading to this review has received funding from People Programme (Marie Curie Actions) of the European Union's Seventh Framework Programme FP7/2007-2013/ under REA grant agreement No. 607868 (iTERM).

\section{Compliance with Ethical Standards}

\section{Conflict of Interest}

The authors declare that they have no conflicts of interest.

Open Access This article is distributed under the terms of the Creative Commons Attribution 4.0 International License (http://creativecommons.org/licenses/by/4.0/), which permits unrestricted use, distribution, and reproduction in any medium, provided you give appropriate credit to the original author(s) and the source, provide a link to the Creative Commons license, and indicate if changes were made.

\section{References}

1. Plewes DB, Kucharczyk W (2012) Physics of MRI: a primer. J Magn Reson Imaging 35:1038-1054

2. Jaffer FA, Weissleder R (2005) Molecular imaging in the clinical arena. J Am Med Assoc 293:855-862

3. Edelman RR (2014) The history of MR imaging as seen through the pages of radiology. Radiology 273:S181-S200

4. Riederer SJ (2004) New advances in MRI. In: Yang GZ, Jiang TZ (eds) Medical imaging and augmented reality. MIAR 2004. Lecture Notes in Computer Science, vol 3150. Springer, Berlin, Heidelberg
5. Horska A, Barker PB (2010) Imaging of brain tumors: MR spectroscopy and metabolic imaging. Neuroimaging Clin $\mathrm{N}$ Am 20:293-310

6. Gore JC (2003) Principles and practice of functional MRI of the human brain. J Clin Invest 112:4-9

7. Low G, Kruse SA, Lomas DJ (2016) General review of magnetic resonance elastography. World J Radiol 8:59-72

8. Holmes JE, Bydder GM (2005) MR imaging with ultrashort TE (UTE) pulse sequences: basic principles. Radiography 11:163-174

9. Currie S, Hoggard N, Craven IJ, Hadjivassiliou M, Wilkinson ID (2013) Understanding MRI: basic MR physics for physicians. Postgrad Med J 89(1050):209-223

10. Keeler J (2002) The vector model. In: Understanding NMR spectroscopy, 2nd edn. Wiley, pp 25-46

11. Hennig J (1999) K-space sampling strategies. Eur Radiol 9:1020-1031

12. Moore MM, Chung T (2017) Review of key concepts in magnetic resonance physics. Pediatr Radiol 47:497-506

13. Stanisz GJ, Odrobina EE, Pun J, Escaravage M, Graham SJ, Bronskill MJ, Henkelman RM (2005) T1, T2 relaxation and magnetization transfer in tissue at 3T. Magn Reson Med 54:507-512

14. Robson MD, Bydder GM (2006) Clinical ultrashort echo time imaging of bone and other connective tissues. NMR Biomed 19:765-780

15. Bydder GM (2011) Review. The Agfa Mayneord lecture: MRI of short and ultrashort $\mathrm{T}(2)$ and $\mathrm{T}(2)^{*}$ components of tissues, fluids and materials using clinical systems. Br J Radiol 84:1067-1082

16. Chang EY, Du J, Chung CB (2015) UTE imaging in the musculoskeletal system. J Magn Reson Imaging 41:870-883

17. Robson MD, Gatehouse PD, Bydder M, Bydder GM (2003) Magnetic resonance: an introduction to ultrashort TE (UTE) imaging. J Comput Assist Tomogr 27:825-846

18. Tyler DJ, Robson MD, Henkelman RM, Young IR, Bydder GM (2007) Magnetic resonance imaging with ultrashort TE (UTE) PULSE sequences: technical considerations. J Magn Reson Imaging 25:279-289

19. Brodsky EK, Samsonov AA, Block WF (2009) Characterizing and correcting gradient errors in non-cartesian imaging: are gradient errors linear time-invariant (LTI)? Magn Reson Med 62:1466-1476

20. Bartusek K, Kubasek R, Fiala P (2010) Determination of pre-emphasis constants for eddy current reduction. Meas Sci Technol 21:105601

21. Addy NO, Wu HH, Nishimura DG (2012) Simple method for MR gradient system characterization and $\mathrm{k}$-space trajectory estimation. Magn Reson Med 68:120-129

22. Vannesjo SJ, Haeberlin M, Kasper L, Pavan M, Wilm BJ, Barmet C, Pruessmann KP (2013) Gradient system characterization by impulse response measurements with a dynamic field camera. Magn Reson Med 69:583-593

23. Jang H, Wiens CN, McMillan AB (2016) Ramped hybrid encoding for improved ultrashort echo time imaging. Magn Reson Med 76:814-825

24. Jang H, McMillan AB (2017) A rapid and robust gradient measurement technique using dynamic single-point imaging. Magn Reson Med 78:950-962

25. Weiger M, Pruessmann KP (2012) MRI with zero echo time. In: Harris RK, Wasylishen RL (eds) eMagRes. https://doi.org/10.1002/ 9780470034590.emrstm1292

26. Weiger M, Pruessmann KP, Hennel F (2011) MRI with zero echo time: hard versus sweep pulse excitation. Magn Reson Med 66:379-389

27. Grodzki DM, Jakob PM, Heismann B (2012) Ultrashort echo time imaging using pointwise encoding time reduction with radial acquisition (PETRA). Magn Reson Med 67:510-518

28. Waldman A, Rees JH, Brock CS, Robson MD, Gatehouse PD, Bydder GM (2003) MRI of the brain with ultra-short echo-time pulse sequences. Neuroradiology 45:887-892

29. Gatehouse PD, Bydder GM (2003) Magnetic resonance imaging of short T2 components in tissue. Clin Radiol 58:1-19

30. Du J, Takahashi AM, Bydder M et al (2009) Ultrashort TE imaging with offresonance saturation contrast (UTE-OSC). Magn Reson Med 62:527-531

31. Du J, Carl M, Bydder M et al (2010) Qualitative and quantitative ultrashort echo time (UTE) imaging of cortical bone. J Magn Reson 207:304-311

32. Chang EY, Bae WC, Shao H, Biswas R, Li S, Chen J, Patil S, Healey R, D'Lima DD, Chung CB, du J (2015) Ultrashort echo time magnetization transfer (UTE-MT) imaging of cortical bone. NMR Biomed 28:873-880

33. Wiens CN, Artz NS, Jang H, McMillan AB, Koch KM, Reeder SB (2018) Fully phase-encoded MRI near metallic implants using 
ultrashort echo times and broadband excitation. Magn Reson Med 79:2156-2163

34. Nazaran A, Carl M, Ma Y, Jerban S, Zhu Y, Lu X, du J, Chang EY (2017) Three-dimensional adiabatic inversion recovery prepared ultrashort echo time cones (3D IR-UTE-Cones) imaging of cortical bone in the hip. Magn Reson Imaging 44:60-64

35. Weiger M, Brunner DO, Dietrich BE, Muller CF, Pruessmann KP (2013) ZTE imaging in humans. Magn Reson Med 70:328-332

36. Wiesinger F, Sacolick LI, Menini A, Kaushik SS, Ahn S, VeitHaibach P, Delso G, Shanbhag DD (2016) Zero TE MR bone imaging in the head. Magn Reson Med 75:107-114

37. Li C, Magland JF, Seifert AC, Wehrli FW (2014) Correction of excitation profile in zero echo time (ZTE) imaging using quadratic phase-modulated RF pulse excitation and iterative reconstruction. IEEE Trans Med Imaging 33:961-969

38. Marcon M, Weiger M, Keller D, Wurnig MC, Eberhardt C, Eberli D, Boss A (2016) Magnetization transfer imaging of cortical bone in vivo using a zero echo time sequence in mice at $4.7 \mathrm{~T}$ : a feasibility study. Magma 29:853-862

39. Lee YH, Suh JS, Grodzki D (2016) Ultrashort echo (UTE) versus pointwise encoding time reduction with radial acquisition (PETRA) sequences at 3 Tesla for knee meniscus: a comparative study. Magn Reson Imaging 34:75-80

40. Schieban K, Weiger M, Hennel F, Boss A, Pruessmann KP (2015) ZTE imaging with enhanced flip angle using modulated excitation. Magn Reson Med 74:684-693

41. Weiger M, Wu M, Wurnig MC, Kenkel D, Boss A, Andreisek G, Pruessmann KP (2015) ZTE imaging with long-T2 suppression. NMR Biomed 28:247-254

42. Idiyatullin D, Corum C, Park JY, Garwood M (2006) Fast and quiet MRI using a swept radiofrequency. J Magn Reson 181:342-349

43. Idiyatullin D, Suddarth S, Corum CA, Adriany G, Garwood M (2012) Continuous SWIFT. J Magn Reson 220:26-31

44. Hahn EL (1950) Spin echoes. Phys Rev 80:580-594

45. Bloch F (1946) Nuclear induction. Phys Rev 70:460-474

46. Blümich B (1984) Stochastic NMR imaging. J Magn Reson (1969) 60:37-45

47. Idiyatullin D, Corum CA, Garwood M (2015) Multi-band-SWIFT. J Magn Reson 251:19-25

48. Zhang J, Idiyatullin D, Corum CA, Kobayashi N, Garwood M (2016) Gradient-modulated SWIFT. Magn Reson Med 75:537-546

49. Zhang J, Nissi MJ, Idiyatullin D, Michaeli S, Garwood M, Ellermann J (2016) Capturing fast relaxing spins with SWIFT adiabatic rotating frame spin-lattice relaxation (T1rho) mapping. NMR Biomed 29:420-430

50. Boskey AL (2013) Bone composition: relationship to bone fragility and antiosteoporotic drug effects. Bonekey Rep 2:447

51. Yaszemski MJ, Payne RG, Hayes WC, Langer R, Mikos AG (1996) Evolution of bone transplantation: molecular, cellular and tissue strategies to engineer human bone. Biomaterials 17:175-185

52. Salgado AJ, Coutinho OP, Reis RL (2004) Bone tissue engineering: state of the art and future trends. Macromol Biosci 4:743-765

53. Orwoll ES (2003) Toward an expanded understanding of the role of the periosteum in skeletal health. J Bone Miner Res 18:949-954

54. Seeman E, Delmas PD (2006) Bone quality-the material and structural basis of bone strength and fragility. N Engl J Med 354:2250-2261

55. Weiner S, Wagner HW (1998) The material bone: structuralmechanical function relations. Annu Rev Mater Sci 28:271-298

56. Beniash E (2010) Biominerals-hierarchical nanocomposites: the example of bone. Wiley Interdiscip Rev Nanomed Nanobiotechnol 3:47-69

57. Fernandez-Seara MA, Wehrli SL, Wehrli FW (2002) Diffusion of exchangeable water in cortical bone studied by nuclear magnetic resonance. Biophys J 82:522-529

58. Bae WC, Chen PC, Chung CB, Masuda K, D'Lima D, du J (2012) Quantitative ultrashort echo time (UTE) MRI of human cortical bone: correlation with porosity and biomechanical properties. J Bone Miner Res 27:848-857

59. Nyman JS, Ni Q, Nicolella DP, Wang X (2008) Measurements of mobile and bound water by nuclear magnetic resonance correlate with mechanical properties of bone. Bone 42:193-199

60. Rad HS, Lam SC, Magland JF et al (2011) Quantifying cortical bone water in vivo by three-dimensional ultra-short echo-time MRI. NMR Biomed 24:855-864
61. Biswas R, Bae W, Diaz E, Masuda K, Chung CB, Bydder GM, du J (2012) Ultrashort echo time (UTE) imaging with bi-component analysis: bound and free water evaluation of bovine cortical bone subject to sequential drying. Bone 50:749-755

62. Goldberg M, Septier D, Lecolle S et al (1995) Dental mineralization. Int J Dev Biol 39:93-110

63. Goldberg M, Kulkarni AB, Young M, Boskey A (2011) Dentin: structure, composition and mineralization. Front Biosci (Elite Ed) 3:711-735

64. Laurance-Young P, Bozec L, Gracia L, Rees G, Lippert F, Lynch RJM, Knowles JC (2011) A review of the structure of human and bovine dental hard tissues and their physicochemical behaviour in relation to erosive challenge and remineralisation. J Dent 39:266-272

65. Teruel Jde D, Alcolea A, Hernandez A, Ruiz AJ (2015) Comparison of chemical composition of enamel and dentine in human, bovine, porcine and ovine teeth. Arch Oral Biol 60:768-775

66. Yamamoto $\mathrm{T}$, Hasegawa $\mathrm{T}$, Yamamoto $\mathrm{T}$, Hongo $\mathrm{H}$, Amizuka N (2016) Histology of human cementum: its structure, function, and development. Jpn Dent Sci Rev 52:63-74

67. Li C, Seifert AC, Rad HS, Bhagat YA, Rajapakse CS, Sun W, Benny Lam SC, Wehrli FW (2016) Cortical bone water concentration: dependence of MR imaging measures on age and pore volume fraction. Radiology 280:653

68. Schreiner LJ, Cameron IG, Funduk N, Miljković L, Pintar MM, Kydon DN (1991) Proton NMR spin grouping and exchange in dentin. Biophys J 59:629-639

69. Reichert IL, Benjamin M, Gatehouse PD et al (2004) Magnetic resonance imaging of periosteum with ultrashort TE pulse sequences. J Magn Reson Imaging 19:99-107

70. Reichert IL, Robson MD, Gatehouse PD et al (2005) Magnetic resonance imaging of cortical bone with ultrashort TE pulse sequences. Magn Reson Imaging 23:611-618

71. Du J, Hamilton G, Takahashi A et al (2007) Ultrashort echo time spectroscopic imaging (UTESI) of cortical bone. Magn Reson Med 58:1001-1009

72. Du J, Takahashi AM, Chung CB (2009) Ultrashort TE spectroscopic imaging (UTESI): application to the imaging of short $\mathrm{T} 2$ relaxation tissues in the musculoskeletal system. J Magn Reson Imaging 29:412-421

73. Du J, Takahashi AM, Bae WC et al (2010) Dual inversion recovery, ultrashort echo time (DIR UTE) imaging: creating high contrast for short-T(2) species. Magn Reson Med 63:447-455

74. Fernandez-Seara MA, Wehrli SL, Takahashi M, Wehrli FW (2004) Water content measured by proton-deuteron exchange NMR predicts bone mineral density and mechanical properties. J Bone Miner Res 19:289-296

75. Horch RA, Gochberg DF, Nyman JS, Does MD (2012) Clinically compatible MRI strategies for discriminating bound and pore water in cortical bone. Magn Reson Med 68:1774-1784

76. Manhard MK, Horch RA, Gochberg DF, Nyman JS, Does MD (2015) In vivo quantitative MR imaging of bound and pore water in cortical bone. Radiology 277:221-229

77. Li S, Ma L, Chang EY, Shao H, Chen J, Chung CB, Bydder GM, du J (2015) Effects of inversion time on inversion recovery prepared ultrashort echo time (IR-UTE) imaging of bound and pore water in cortical bone. NMR Biomed 28:70-78

78. Chen J, Carl M, Ma Y, Shao H, Lu X, Chen B, Chang EY, Wu Z, du J (2016) Fast volumetric imaging of bound and pore water in cortical bone using three-dimensional ultrashort-TE (UTE) and inversion recovery UTE sequences. NMR Biomed 29:1373-1380

79. Abbasi-Rad S, Saligheh Rad H (2017) Quantification of human cortical bone bound and free water in vivo with ultrashort echo time MR imaging: a model-based approach. Radiology 283:862-872

80. Geiger D, Bae WC, Statum S, du J, Chung CB (2014) Quantitative 3D ultrashort time-to-echo (UTE) MRI and micro-CT (muCT) evaluation of the temporomandibular joint (TMJ) condylar morphology. Skelet Radiol 43:19-25

81. Serai SD, Laor T, Dwek JR, Zbojniewicz AM, Carl M (2014) Feasibility of ultrashort TE (UTE) imaging of children at $1.5 \mathrm{~T}$. Pediatr Radiol 44:103-108

82. Ma YJ, Zhu Y, Lu X, Carl M, Chang EY, du J (2018) Short T2 imaging using a 3D double adiabatic inversion recovery prepared ultrashort echo time cones (3D DIR-UTE-cones) sequence. Magn Reson Med 79:2555-2563

83. Ma YJ, Chang EY, Carl M, Du J (2018) Quantitative magnetization transfer ultrashort echo time imaging using a time-efficient 3D multispoke cones sequence. Magn Reson Med 79:692-700 
84. Robson MD, Gatehouse PD, Bydder GM, Neubauer S (2004) Human imaging of phosphorus in cortical and trabecular bone in vivo. Magn Reson Med 51:888-892

85. Wu Y, Reese TG, Cao H, Hrovat MI, Toddes SP, Lemdiasov RA, Ackerman JL (2011) Bone mineral imaged in vivo by ${ }^{31} \mathrm{P}$ solid state MRI of human wrists. J Magn Reson Imaging 34:623-633

86. Robson MD, Tyler DJ, Neubauer S (2005) Ultrashort TE chemical shift imaging (UTE-CSI). Magn Reson Med 53:267-274

87. Wu Y, Ackerman JL, Chesler DA, Graham L, Wang Y, Glimcher MJ (2003) Density of organic matrix of native mineralized bone measured by water- and fat-suppressed proton projection MRI. Magn Reson Med 50:59-68

88. Wu Y, Dai G, Ackerman JL, Hrovat MI, Glimcher MJ, Snyder BD, Nazarian A, Chesler DA (2007) Water- and fat-suppressed proton projection MRI (WASPI) of rat femur bone. Magn Reson Med 57:554-567

89. Weiger M, Stampanoni M, Pruessmann KP (2013) Direct depiction of bone microstructure using MRI with zero echo time. Bone 54:44-47

90. Larson PE, Han M, Krug R et al (2016) Ultrashort echo time and zero echo time MRI at 7T. Magma 29:359-370

91. Seifert AC, Li C, Rajapakse CS, Bashoor-Zadeh M, Bhagat YA, Wright AC, Zemel BS, Zavaliangos A, Wehrli FW (2014) Bone mineral ${ }^{31} \mathrm{P}$ and matrix-bound water densities measured by solid-state ${ }^{31} \mathrm{P}$ and ${ }^{1} \mathrm{H}$ MRI. NMR Biomed 27:739-748

92. Zhao X, Song HK, Seifert AC, Li C, Wehrli FW (2017) Feasibility of assessing bone matrix and mineral properties in vivo by combined solid-state ${ }^{1} \mathrm{H}$ and ${ }^{31} \mathrm{P}$ MRI. PLoS One 12:e0173995

93. Boujraf SHC, Ulrici J, Hell E, Rasche V (2009) Microstructural assessment of dental tissues by quantitative MRI using ultra-short echo times (UTE): initial in-vivo evaluation [abstract]. 17th Annual Meeting of ISMRM: 18-24

94. Idiyatullin D, Corum C, Moeller S, Prasad HS, Garwood M, Nixdorf DR (2011) Dental magnetic resonance imaging: making the invisible visible. J Endod 37:745-752

95. Weiger M, Pruessmann KP, Bracher AK, Köhler S, Lehmann V, Wolfram U, Hennel F, Rasche V (2012) High-resolution ZTE imaging of human teeth. NMR Biomed 25:1144-1151

96. Bracher AK, Hofmann C, Bornstedt A, Boujraf S, Hell E, Ulrici J, Spahr A, Haller B, Rasche V (2011) Feasibility of ultra-short echo time (UTE) magnetic resonance imaging for identification of carious lesions. Magn Reson Med 66:538-545

97. Bracher AK, Hofmann C, Bornstedt A, Hell E, Janke F, Ulrici J, Haller B, Geibel MA, Rasche V (2013) Ultrashort echo time (UTE) MRI for the assessment of caries lesions. Dentomaxillofac Radiol 42:20120321

98. Idiyatullin D, Garwood M, Gaalaas L, Nixdorf DR (2016) Role of MRI for detecting micro cracks in teeth. Dentomaxillofac Radiol 45:20160150

99. Rychert KM, Zhu G, Kmiec MM et al (2015) Imaging tooth enamel using zero echo time (ZTE) magnetic resonance imaging. Proc SPIE Int Soc Opt Eng 9417

100. Sun Y, Brauckmann O, Nixdorf DR, Kentgens A, Garwood M, Idiyatullin D et al (2016) Imaging human teeth by phosphorus magnetic resonance with nuclear overhauser enhancement. Sci Rep 6:30756

101. Hovener JB, Zwick S, Leupold J et al (2012) Dental MRI: imaging of soft and solid components without ionizing radiation. J Magn Reson Imaging 36:841-846

102. Idiyatullin D, Corum CA, Nixdorf DR, Garwood M (2014) Intraoral approach for imaging teeth using the transverse B1 field components of an occlusally oriented loop coil. Magn Reson Med 72:160-165
103. Ludwig U, Eisenbeiss AK, Scheifele C, Nelson K, Bock M, Hennig J, von Elverfeldt D, Herdt O, Flügge T, Hövener JB (2016) Dental MRI using wireless intraoral coils. Sci Rep 6:23301

104. Stevens MM (2008) Biomaterials for bone tissue engineering. Mater Today 11:18-25

105. Sheikh Z, Najeeb S, Khurshid Z, Verma V, Rashid H, Glogauer M (2015) Biodegradable materials for bone repair and tissue engineering applications. Materials (Basel) 8:5744-5794

106. Goodrich JT, Sandler AL, Tepper O (2012) A review of reconstructive materials for use in craniofacial surgery bone fixation materials, bone substitutes, and distractors. Childs Nerv Syst 28:1577-1588

107. Emid S, Creyghton JHN (1985) High resolution NMR imaging in solids. Physica B+C 128:81-83

108. Jang $\mathrm{H}$, Lu X, Carl $\mathrm{M}$ et al (2018) True phase quantitative susceptibility mapping using continuous single-point imaging: a feasibility study. Magn Reson Med

109. Springer F, Steidle G, Martirosian P, Syha R, Claussen CD, Schick F (2011) Rapid assessment of longitudinal relaxation time in materials and tissues with extremely fast signal decay using UTE sequences and the variable flip angle method. Investig Radiol 46(10):610-617

110. Grosse U, Syha R, Papanikolaou D, Martirosian P, Grözinger G, Schabel C, Schick F, Springer F (2013) Magnetic resonance imaging of solid dental restoration materials using 3D UTE sequences: visualization and relaxometry of various compounds. Magma 26:555-564

111. Sun Y, Ventura M, Oosterwijk E, Jansen JA, Walboomers XF, Heerschap A (2013) Zero echo time magnetic resonance imaging of contrast-agent-enhanced calcium phosphate bone defect fillers. Tissue Eng Part C Methods 19:281-287

112. Ventura M, Sun Y, Rusu V, Laverman P, Borm P, Heerschap A, Oosterwijk E, Boerman OC, Jansen JA, Walboomers XF (2013) Dual contrast agent for computed tomography and magnetic resonance hard tissue imaging. Tissue Eng Part C Methods 19:405-416

113. Mastrogiacomo S, Kownacka AE, Dou W et al (2018) Bisphosphonate functionalized gadolinium oxide nanoparticles allow long-term $\mathrm{MRI} / \mathrm{CT}$ multimodal imaging of calcium phosphate bone cement. Adv Healthc Mater 7:e1800202

114. Mastrogiacomo S, Dou W, Koshkina O, Boerman OC, Jansen JA, Heerschap A, Srinivas M, Walboomers XF (2017) Perfluorocarbon/ gold loading for noninvasive in vivo assessment of bone fillers using (19) F magnetic resonance imaging and computed tomography. ACS Appl Mater Interfaces 9:22149-22159

115. Dou W, Mastrogiacomo S, Veltien A et al (2018) Visualization of calcium phosphate cement in teeth by zero echo time ${ }^{1} \mathrm{H}$ MRI at high field. NMR Biomed 31. https://doi.org/10.1002/nbm.3859

116. Niraj LK, Patthi B, Singla A et al (2016) MRI in dentistry- a future towards radiation free imaging - systematic review. J Clin Diagn Res 10:Ze14-ze19

117. Panych LP, Madore B (2018) The physics of MRI safety. J Magn Reson Imaging 47:28-43

118. Mastrogiacomo S, Guvener N, Dou W et al (2017) A theranostic dental pulp capping agent with improved MRI and CT contrast and biological properties. Acta Biomater 62:340-351

119. Sarracanie M, LaPierre CD, Salameh N et al (2015) Low-cost highperformance MRI. Sci Rep 5:15177

Publisher's Note. Springer Nature remains neutral with regard to jurisdictional claims in published maps and institutional affiliations. 